\title{
Mini-Review
}

\section{Synthesis of Allenes by 1,2-Elimination}

\author{
Roly J. Armstrong *a \\ ${ }^{a}$ Department of Chemistry, Chemical Research Laboratory, University of Oxford, Oxford, OX1 3TA, United Kingdom
}

\begin{abstract}
A R T I C L E H I S T O R Y
Received:

Revised:

Accepted:

DOI:

\begin{tabular}{l} 
A R T I C L E H I S T O R Y \\
\hline Received: \\
Revised: \\
Accepted: \\
DOI:
\end{tabular}

Abstract: Allenes represent an extremely important class of organic molecules, which, as a result of their twisted orthogonal $\pi$-systems can possess axial chirality. A wide array of methods for allene synthesis have been reported, such as substitution of propargylic electrophiles, isomerization of alkynes and sigmatropic rearrangement. An alternative approach for the synthesis of allenes is 1,2-elimination of an appropriately substituted precursor. This mini-review highlights recent examples of 1,2-elimination processes which target allenes including both polar and radical processes. The main focus is upon how control over the stereospecificity (e.g. syn- or anti-) of the 1,2-elimination process can enable the synthesis of enantioenriched axially chiral allenes. Recent developments in this field are presented including both enantiospecific and catalytic asymmetric methods.
\end{abstract}

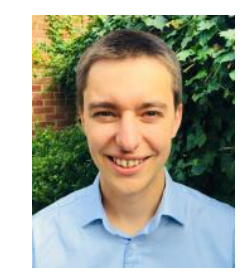

Keywords: Allenes, Cumulenes, Elimination, Stereospecific, Enantiospecific, Axial Chirality.

\section{INTRODUCTION}

Allenes are a fascinating class of organic molecules which are versatile intermediates in organic synthesis and also have numerous applications in materials science, catalysis and medicinal chemistry. ${ }^{[1]}$ The unusual reactivity pattern of allenes stems from the consecutive arrangement of two orthogonal $\pi$-systems. This arrangement also generates a $90^{\circ}$ twist along the axis of the allene which results in axial chirality. A wide variety of methods have been developed for the synthesis of allenes, many of which allow control over absolute stereochemistry. Perhaps the most commonly employed approaches for allene synthesis involve addition of organometallic nucleophiles to propargylic electrophiles (Scheme 1, route a) or the reaction between a propargylic nucleophile and an electrophile (route b). ${ }^{[2]}$ Isomerization of propargyl substrates is another tactic which is also frequently employed (route c). ${ }^{[3]}$

More recently, other efficient routes based on transition metal mediated coupling reactions between alkynes and

\footnotetext{
*Address correspondence to this author at the Department of Chemistry, Chemical Research Laboratory, 12 Mansfield Road, University of Oxford, Oxford, OX1 3TA Tel/Fax: +441865 275964, +441865 285002 E-mail: roland.armstrong@chem.ox.ac.uk
}

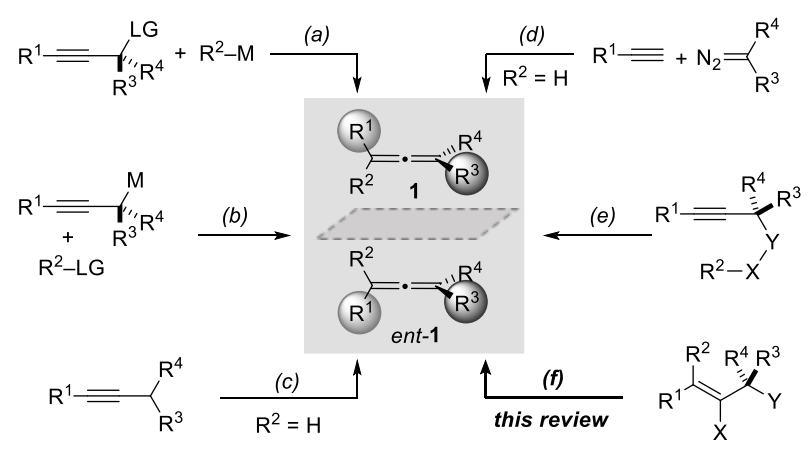

Scheme 1. General methods for the synthesis of allenes. $\mathrm{LG}=$ leaving group; $\mathrm{M}=$ metal (complex).

carbene equivalents (route d) ${ }^{[4]}$ and sigmatropic rearrangements (route e) ${ }^{[5]}$ have also been reported. Numerous elegant examples have been disclosed from all of these categories and this work has been reviewed extensively elsewhere. ${ }^{[6]}$ The topic of this mini-review is the synthesis of allenes by 1,2-elimination (route f). In such processes, a precursor containing a single alkene along with two vicinal groups ( $\mathrm{X}$ and $\mathrm{Y}$ ) is induced to undergo an elimination process to form the corresponding allene. If a chiral non- 
racemic precursor is employed $\left(\mathrm{R}^{1} \neq \mathrm{R}^{2}\right.$ and $\left.\mathrm{R}^{3} \neq \mathrm{R}^{4}\right)$ then it is possible for the point chirality of the starting material to be stereospecifically transferred to axial chirality in the allene product. This provides an excellent opportunity for the asymmetric synthesis of allenes, but syn- and antielimination processes result in formation of opposite enantiomers of the allene product (e.g. 1 vs ent-1). Controlling the nature of the elimination process is therefore critical to obtain highly enantioenriched allene products.

This mini-review highlights examples of 1,2-elimination processes which generate allenes including both polar and radical processes and covers the period up to January 2019. The main focus is upon processes which enable the synthesis of chiral non-racemic allenes, although key examples involving racemic allenes are also presented.

\subsection{Elimination of hydrogen}

Synthesis of allenes by elimination of a proton and a leaving group is a conceptually straightforward process to obtain allenes 3 (Scheme 2). However, this process is often complicated by competing elimination of a vinylic proton to form the corresponding alkynes 4 .

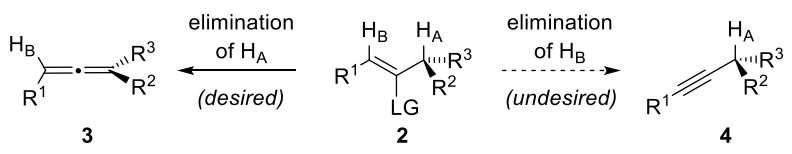

Scheme 2. Competing pathways for proton elimination

Nevertheless, several efficient methods for the synthesis of allenes by such elimination methods have been disclosed. ${ }^{[7]}$ For example, Brummond and co-workers have reported an interesting protocol involving kinetic deprotonation of ketones followed by phosphorylation. ${ }^{[8]}$ The resulting enol phosphates 6 were converted to disubstituted allenes 7 by treatment with LDA (Scheme 3). Impressive selectivity was observed for the desired allene products over alkynes. The reaction could be used to construct a range of allene products including macrocycles such as $\mathbf{7 c}$.

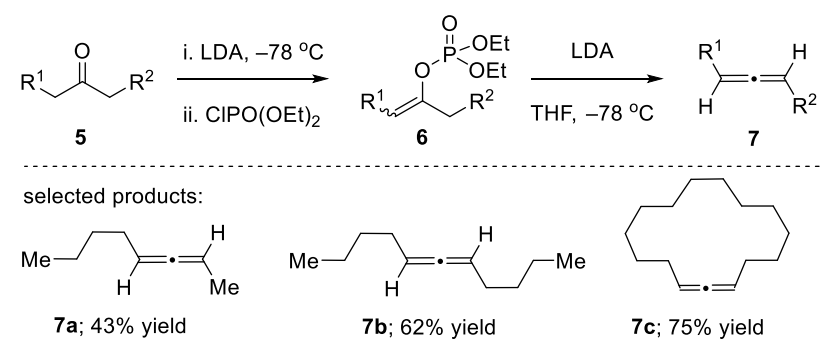

Scheme 3. Synthesis of allenes by elimination of vinyl phosphates

Several groups have reported facile allene syntheses involving halide elimination from electron deficient alkenes. ${ }^{[9]}$ For example, Oh and co-workers have reported that $\beta$-halovinyl ketones 8 can undergo elimination under mildly basic conditions to afford a mixture of allenes $\mathbf{9}$ and alkynes 10 (Scheme 4). ${ }^{[10]}$ The authors carried out a combined experimental and theoretical study which suggested that these reactions do not proceed via simple 1,2elimination. ${ }^{[10]}$ Instead, it is proposed that enolization of the vinyl starting material generates allenol 11, which then undergoes facile elimination to form cumulenol 12. Finally, isomerization affords alkynyl enol $\mathbf{1 3}$ which can undergo protonation at either the $\gamma$ - or $\alpha$-position to produce allene or alkyne products respectively.

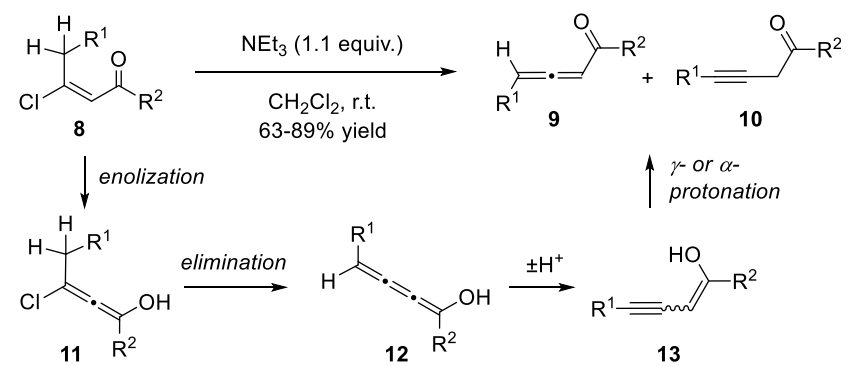

Scheme 4. Synthesis of allenes from $\beta$-halovinyl ketones and proposed mechanism

Uemura and co-workers have reported an asymmetric synthesis of allenes by selenoxide elimination. ${ }^{[1]}$ Asymmetric oxidation of vinyl selenide $\mathbf{1 5}$ under modified Sharpless conditions (with dicyclohexyltartrate as a chiral ligand) afforded enantioenriched selenoxide 16 (Scheme 5a). The resulting selenoxide then underwent elimination to provide sulfonylallene $\mathbf{1 7}$ in high yield, but with modest enantioselectivity (up to 71:29 e.r.). Later it was shown that a selenide bearing a ferrocene derived chiral auxiliary could undergo highly diastereoselective oxidation with $m$-CPBA (Scheme $5 \mathrm{~b}$ ). ${ }^{[12]}$ In this case selenoxide oxidation delivered highly enantioenriched allene products $\mathbf{1 9}$ in up to 94.5:5.5 e.r. Honda et al. reported that vinyl selenides 20 can be oxidized with $m$-CPBA and then undergo enantiospecific $s y n$-selenoxide elimination to form diastereoisomerically pure allenes 22 (Scheme 5c). ${ }^{[13]}$

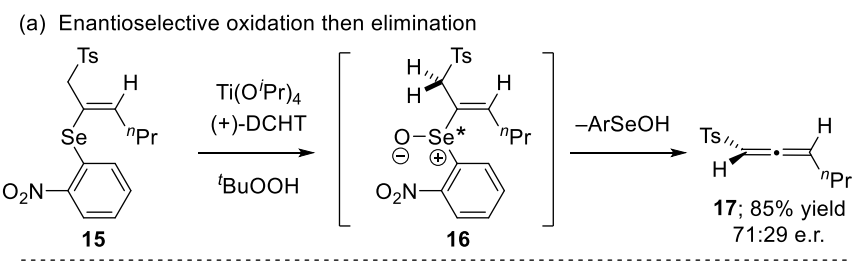

(b) Diastereoselective oxidation then elimination

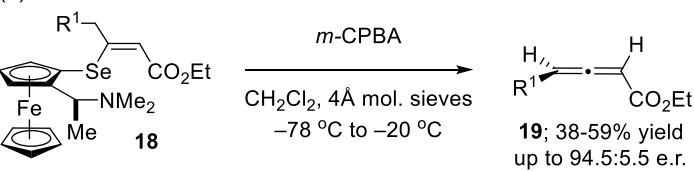

(c) Diastereoselective selenoxide elimination

$$
\underset{\mathrm{PhMe}, 0{ }^{\circ} \mathrm{C}}{\longrightarrow} \underset{\mathrm{R}_{20}}{\stackrel{m \text {-CPBA }}{\longrightarrow}}
$$

Scheme 5. Asymmetric synthesis of allenes by selenoxide elimination

Frantz and co-workers have reported a new method for the enantioselective synthesis of disubstituted allenes by palladium catalyzed $\beta$-hydride elimination (Scheme 6). ${ }^{[14]}$ Two novel phosphoramidite ligands (25 and $\mathbf{2 5}$ ') were 
developed to facilitate the conversion of $E$-vinyl triflates to the corresponding allenes $\mathbf{2 4}$ with very high levels of enantioselectivity. This initial methodology was limited to the synthesis of disubstituted allenes, but recent work from the Frantz group using a $\mathrm{Pd}_{2}(\mathrm{dba})_{3} / \mathrm{P}(\mathrm{OR})_{3}$ system has shown that a similar approach can also be used to synthesize racemic tri- and tetra-substituted allenes. ${ }^{[15]}$

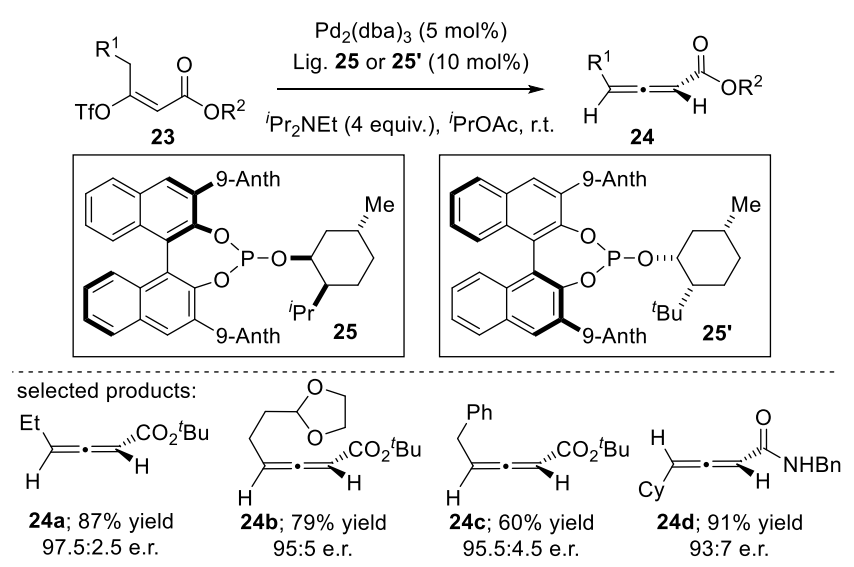

Scheme 6. Asymmetric Pd-catalyzed $\beta$-hydride elimination

The groups of Baudoin and Frantz have both reported Hecktype processes for the synthesis of racemic allenes. ${ }^{[16]}$ Baudoin and co-workers found that aryl bromides could be reacted with alkynes in the presence of $\mathrm{Pd}_{2}(\mathrm{dba})_{3}$ and an electron rich phosphine ligand 26 (Scheme 7a). ${ }^{[17]}$ Interestingly, the addition of pivalic acid was essential to achieve high conversion to the allene products. Frantz and Neff disclosed a coupling of aryl triflates with alkynes under biphasic reaction conditions with a Pd-BobCat complex - in this case the water-soluble dba ligand is extracted into the aqueous phase, preventing deleterious side reactions (Scheme 7b). ${ }^{[18]}$

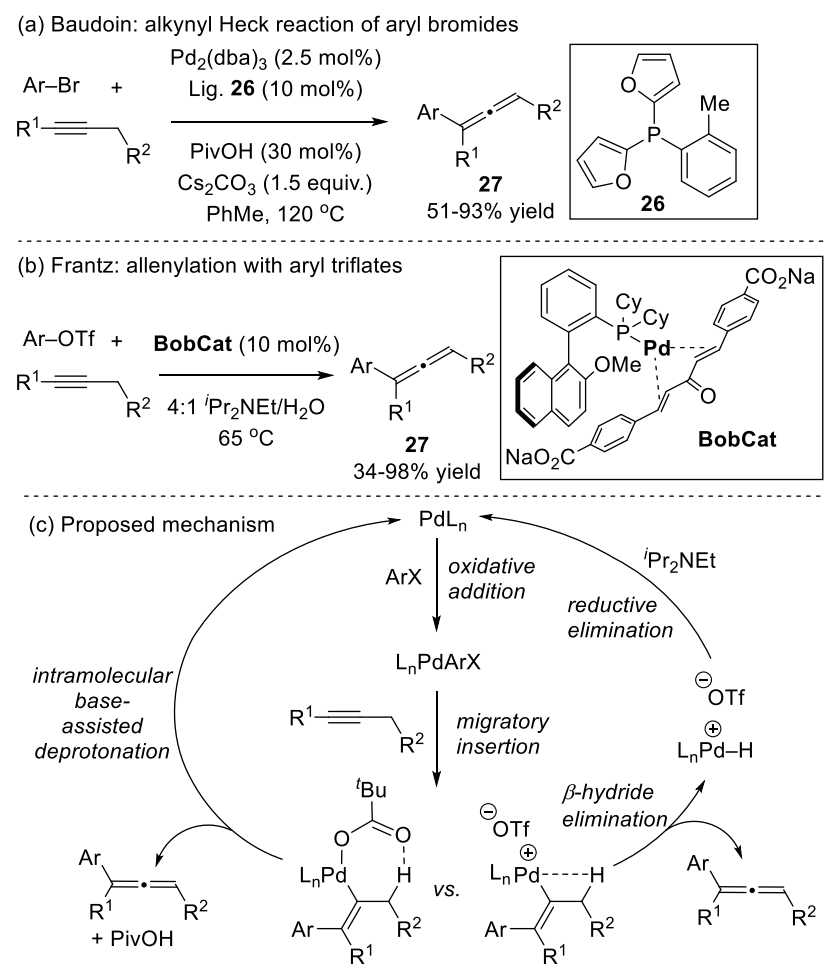

Scheme 7. Synthesis of allenes via Heck-type processes Mechanistically, it is proposed that both of these processes initiate with oxidative addition of $\operatorname{Pd}(0)$ to the aryl electrophile, followed by migratory insertion to generate a vinyl palladium(II) species (Scheme 7c). In the presence of pivalate (Baudoin conditions) it is thought that intramolecular base-assisted deprotonation occurs to directly form the allene product. With vinyl triflates, Frantz and coworkers propose a cationic palladium intermediate is generated, which undergoes $\beta$-hydride elimination followed by reductive elimination.

\subsection{Elimination of phosphorus}

1,2-Elimination of oxygen and phosphorus by Wittig or Horner-Wadsworth-Emmons (HWE) type processes is a well-documented method for allene synthesis and has been reviewed previously. ${ }^{[6 a]}$ There are two possibilities for this type of elimination as the phosphonium (or phosphoester) can be located at either the vinylic or allylic position (Scheme 8).
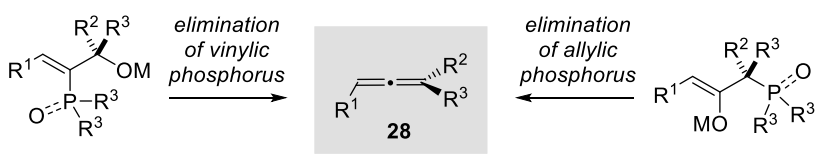

Scheme 8. Synthesis of allenes by elimination of phosphorus

\subsubsection{Elimination of vinylic phosphorus}

A pioneering example of 1,2-elimination of a vinyl phosphine oxide was reported by Wang and co-workers (Scheme 9). ${ }^{[19]}$ In this case, lithium halogen exchange of vinyl iodide 29 followed by reaction with aldehyde $\mathbf{3 0}$ at $-78^{\circ} \mathrm{C}$ generated lithium alkoxide 31. Upon warming to room temperature, spontaneous elimination was observed to form achiral allene $\mathbf{3 2}$ in $74 \%$ yield.

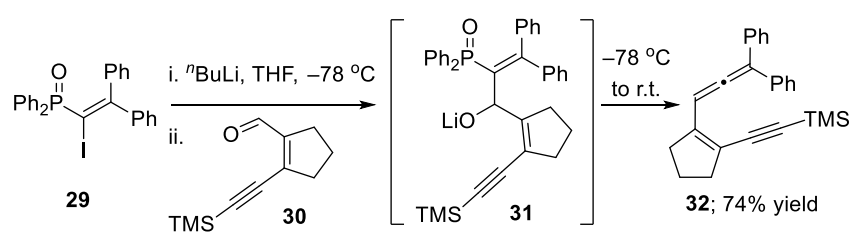

Scheme 9. Elimination of a vinyl phosphine oxide

Tomioka and co-workers subsequently extended this process to a Horner-Wadsworth-Emmons olefination (Scheme 10). ${ }^{[20,21]}$ Vinyl phosphate substrates 33 were directly lithiated with LDA and reacted with aldehydes. Notably, in this case the intermediate lithium alkoxide did not undergo spontaneous elimination. It was proposed that this is because elimination would proceed via an unfavorable strained oxaphosphatane intermediate 36-Li. Ultimately, isolation of the $\beta$-hydroxy phosphonate intermediates $\mathbf{3 4}$ followed by treatment with $\mathrm{KH}$ in the presence of a crown ether afforded allenes 37 in good yields. Presumably, formation of oxaphosphatane $\mathbf{3 6}$ becomes favorable with a more reactive, naked oxyanion. Similar methods have also been reported for the synthesis of racemic allenes bearing thioethers, ${ }^{[2]}$ 
selenoethers, ${ }^{[23]}$ vinyl groups, ${ }^{[24]}$ arenes, ${ }^{[25]}$ alkynes, ${ }^{[26]}$ and esters. ${ }^{[27]}$

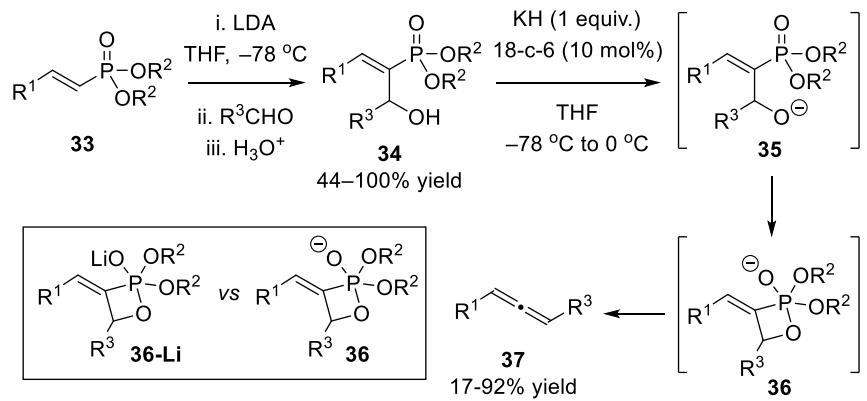

Scheme 10. Allene synthesis by Horner-WadsworthEmmons olefination

An interesting application to asymmetric synthesis has been reported by the Warren group, who showed that vinylic phosphine oxide 38 could be reacted with chiral lithium amide 39 and pivaldehyde providing enantioenriched $\beta$ hydroxy phosphonates 40 (Scheme 11). ${ }^{[28]}$ This reaction was proposed to take place via an addition elimination mechanism analogous to the Baylis-Hillman reaction. Subsequent treatment of intermediate $\mathbf{4 0}$ with $\mathrm{NaH}$ in DMF resulted in stereospecific syn-elimination to form the corresponding allene $\mathbf{4 1}$ which was isolated in good yield albeit with modest enantioenrichment.

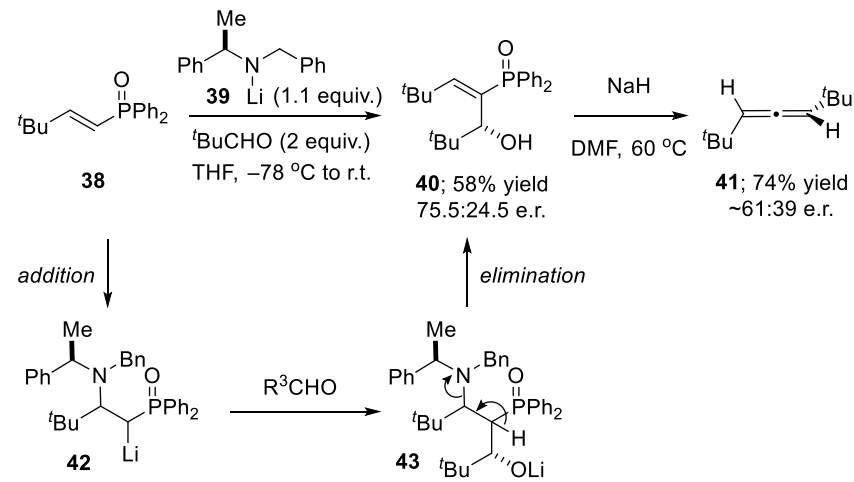

Scheme 11. Asymmetric synthesis of allenes from vinylic phosphine oxides

\subsubsection{Elimination of allylic phosphorus}

Numerous examples have been reported involving the synthesis of racemic allenes by Wittig or HornerWadsworth-Emmons (HWE) olefination reactions with ketenes. ${ }^{[2]}$ For example, Sano and co-workers have recently reported a reaction between phosphonoacetates $\mathbf{4 4}$ and in situ generated ketenes to obtain di-, tri- and tetrasubstituted allenes 45 (Scheme 12a). ${ }^{[30]}$ This reaction proceeds by deprotonation of the phosphonoacetate with isopropylmagnesium bromide to generate magnesium enolate 46. Subsequent reaction with a ketene followed by syn-1,2-elimination then delivers the corresponding allene. Pinho e Melo and co-workers recently disclosed a one-pot method for olefination of acid chlorides with tetrazole containing phosphonium salt 49 (Scheme 12b). ${ }^{[31]}$ This process requires two equivalents of triethylamine. The first deprotonates the phosphonium salt to form an ylide and the second generates a ketene in situ. A range of tetrazole substituted allenes $\mathbf{5 0}$ were obtained in good yields and could be converted to a range of useful heterocyclic derivatives.

(a) Synthesis of allenes by HWE olefination of ketenes

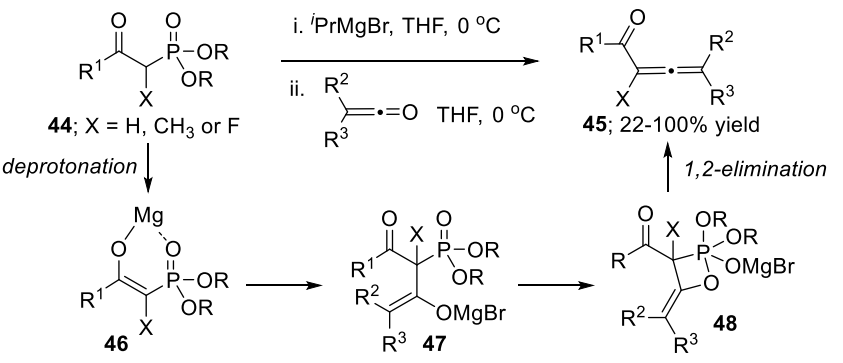

(b) Synthesis of tetrazole substituted allenes by Wittig reaction

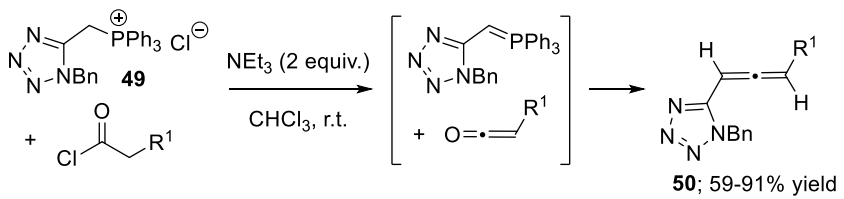

Scheme 12. Synthesis of allenes by HWE and Wittig olefination

The first asymmetric Wittig reaction for the synthesis of chiral non-racemic allenes was reported by Tömösközi and Bestmann in 1964 (Scheme 13a). ${ }^{[32]}$ In this process, acid chlorides were reacted with stabilized ylides bearing a chiral auxiliary (such as menthol derived 51). Diastereomerically enriched allene products $\mathbf{5 2}$ were obtained, but the yield and diastereoselectivity were not reported. Musierowicz et al. later developed an asymmetric Horner-Wadsworth-Emmons approach for the synthesis of allenoates (Scheme 13b). ${ }^{[33]}$ Chiral at phosphorus reagent $\mathbf{5 3}$ was employed in this study, which could be reacted with ketenes in the presence of $\mathrm{NaH}$ to obtain chiral allenes $\mathbf{5 4}$ in up to 59.5:40.5 e.r.

(a): Tömösközi and Bestmann - asymmetric Wittig reaction

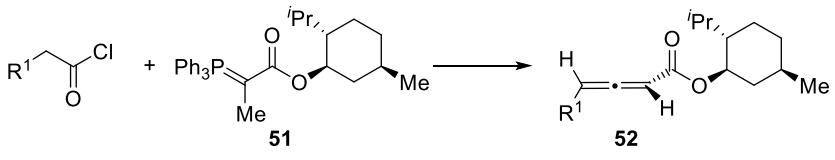

(b): Musierowicz et al. - asymmetric HWE reaction

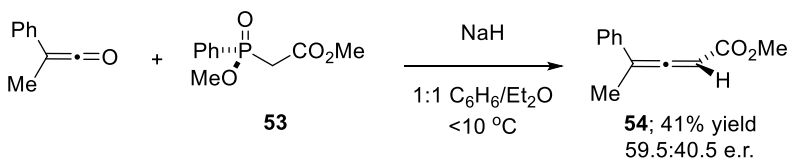

Scheme 13. Early examples of asymmetric allene synthesis by Wittig and HWE reactions

Fuji, and co-workers have reported a process in which ketenes (generated in situ by base mediated elimination of BHT esters 57) were reacted with BINOL derived phosphonoacetate 55 to afford enantioenriched allenes 56 in excellent yields (Scheme 14). ${ }^{[34]}$ The levels of enantioselectivity obtained in this reaction were generally quite variable, but in some cases highly enantioenriched allenes could be isolated (for example, compare 56a with 56b). A similar method has also been reported in which allenes were generated from phenyl esters. ${ }^{[35]}$ 


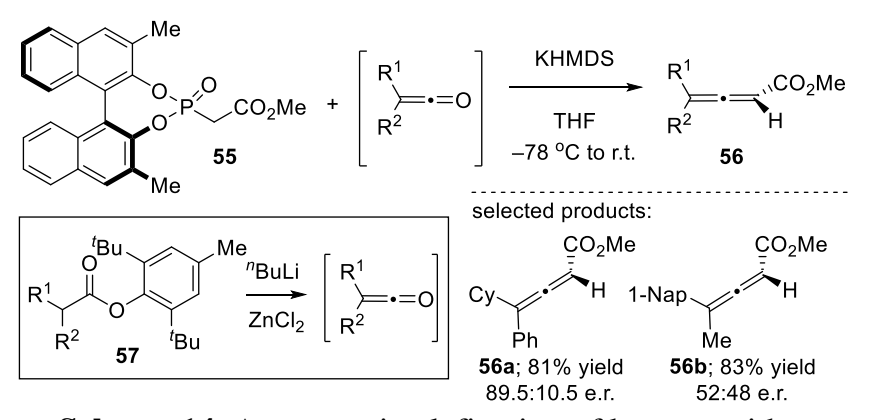

Scheme 14. Asymmetric olefination of ketenes with a BINOL derived phosphonoacetate

Pinho e Melo et al. have shown that ylide 58, bearing a 10-(phenylsulfonyl)isoborneol auxiliary can be reacted with in situ generated ketenes to form allenes (Scheme 15). ${ }^{[36]} \mathrm{A}$ series of products bearing various aliphatic substituents (such as 59a-c) were isolated in high yields and with complete diastereocontrol. It was also demonstrated that the products could readily be saponified to the corresponding carboxylic acids. Allenes of the opposite absolute configuration could be obtained employing an enantiomeric isoborneol auxiliary.

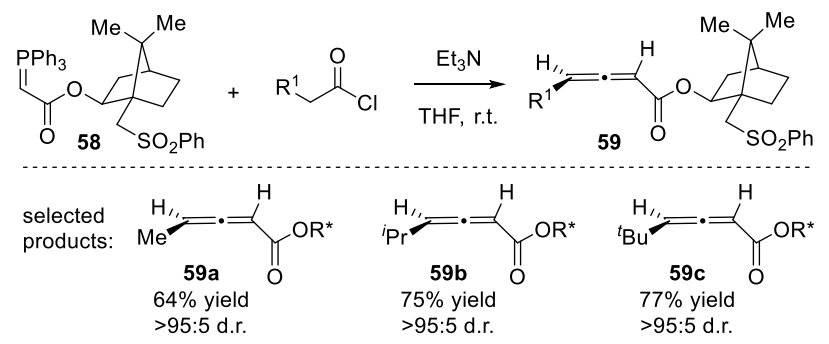

Scheme 15. Highly diastereoselective synthesis of allenes by Wittig olefination

Tang and co-workers have introduced C2-symmetrical phosphonium salt 60, which was prepared in four steps from a commerically available diketone (Scheme 16). ${ }^{[37]}$ The corresponding ylide was formed with NaHMDS and was reacted with ketenes to afford chiral trisubstituted allenes $\mathbf{6 1}$ in good to excellent yields. The enantioselectivities obtained with this method were very high for ethyl substituted allenes such as 61a and 61b although were significantly lower with other alkyl substituents (e.g. 61c). The phosphine oxide byproduct $\mathbf{6 2}$ formed in this reaction could be isolated and then efficiently recycled to reform phosphonium salt $\mathbf{6 0}$.

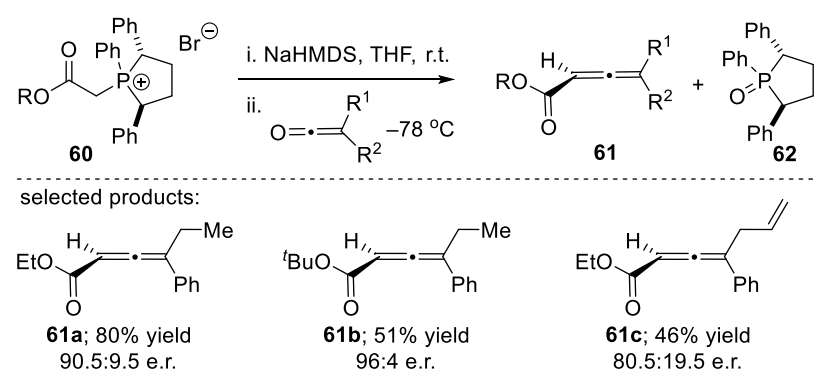

Scheme 16. Synthesis of enantioenriched allenes using a C2-symmetrical phosphonium salt
Tang, Zhou and co-workers have developed an efficient catalytic synthesis of chiral allenes from ketenes (Scheme 17).${ }^{[38]}$ In this process, a stoichiometric chiral MeO-BIPHEP derivative 63 was treated with ethyl diazoacetate and $0.5 \mathrm{~mol} \%$ of tetra( $p$-chlorophenyl)porphyrin iron chloride $(\mathrm{Fe}(\mathrm{TCP}) \mathrm{Cl})$ followed by the addition of disubstituted ketenes. Allenes 64 were obtained in high yields and with excellent levels of enantioselectivity. Mechanistically, it thought that the reaction is initiated by formation of an iron carbenoid 65 which then reacts with the chiral bisphosphine to generate a free ylide 66. Subsequent reaction of $\mathbf{6 6}$ with ketenes generates the enantioenriched allene products. Control experiments were carried out which revealed that only one of the two phosphines in chiral bisphosphine $\mathbf{6 3}$ undergoes activation.

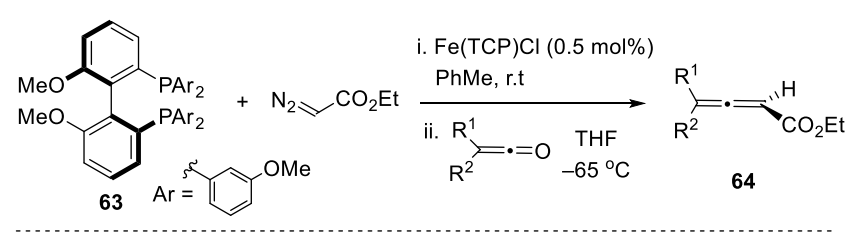

selected products:
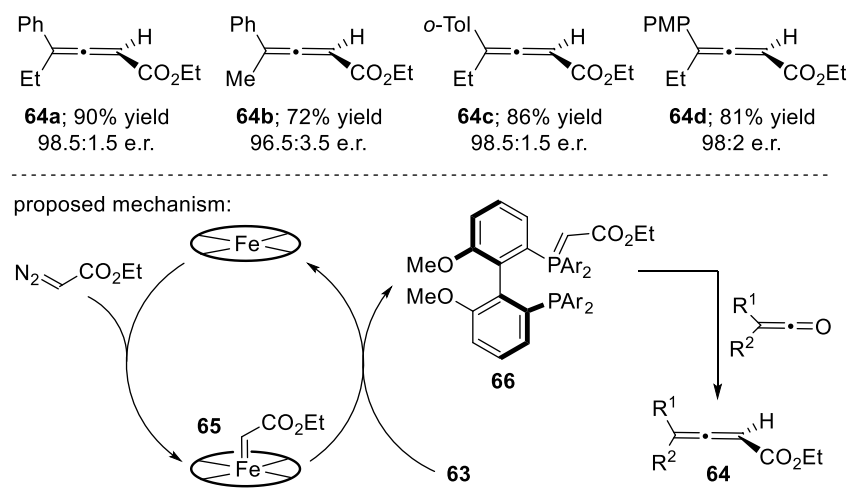

Scheme 17. Iron-porphyrin catalyzed asymmetric synthesis of chiral allenes. TCP $=$ tetra $(p$-chlorophenyl $)$ porphyrin.

\subsection{Elimination of silicon}

Synthesis of allenes by elimination of silicon and oxygen via Peterson-type chemistry has been investigated by several groups. In a similar manner to the analogous reactions with vinyl phosphates (Section 2.2), the 1,2-elimination step is often challenging due to the highly strained nature of the required cyclic silicate intermediate $\mathbf{6 9}$ (Scheme 18).

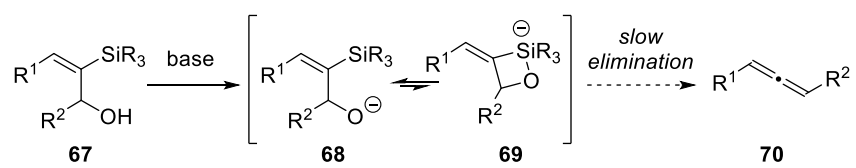

Scheme 18. Challenging elimination in Peterson allenylation

However, several useful procedures have been developed which overcome this challenge. Takeda and co-workers reported that $\beta$-hydroxysilanes $\mathbf{7 1}$ could be deprotonated with $n$-BuLi in $\mathrm{Et}_{2} \mathrm{O}$ to generate lithium alkoxides 72 which were resistant to elimination (Scheme 19a). ${ }^{[39]}$ Upon addition of dimethylformamide (DMF) and warming to $50^{\circ} \mathrm{C}$, smooth elimination to the desired allenes $\mathbf{7 3}$ was observed. It was proposed that the increase in solvent polarity favours formation of the required cyclic silicate intermediate. 
Danishefsky et al. found that bis-trimethylsilylvinyl alcohol 74 could be deprotonated with $n$-BuLi and then treated with $\mathrm{KO}^{t} \mathrm{Bu}$ to effect transformation to the corresponding allene 76 (Scheme 19b). ${ }^{[40]}$ Mechanistically, a sequence involving transmetalation, Brook rearrangement and elimination was proposed to account for this result. The majority of silyl allenes in this study were not isolated, but were isomerized directly to the corresponding alkynes. Another possibility is to convert the alcohol to a better leaving group. For example, a chlorination-elimination strategy was introduced by Chan and co-workers, ${ }^{[41]}$ and later developed by Tius et al. ${ }^{[42]}$ enabling the synthesis of allenes $\mathbf{8 1}$ in good yields (Scheme $19 \mathrm{c})$.

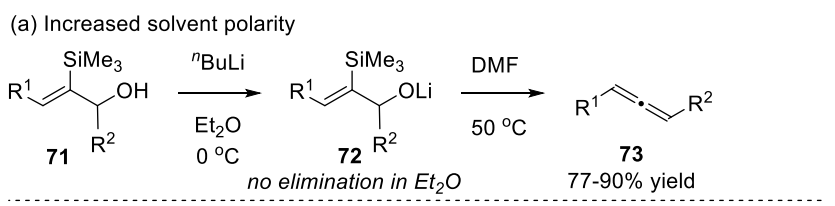

(b) Change counterion to potassium

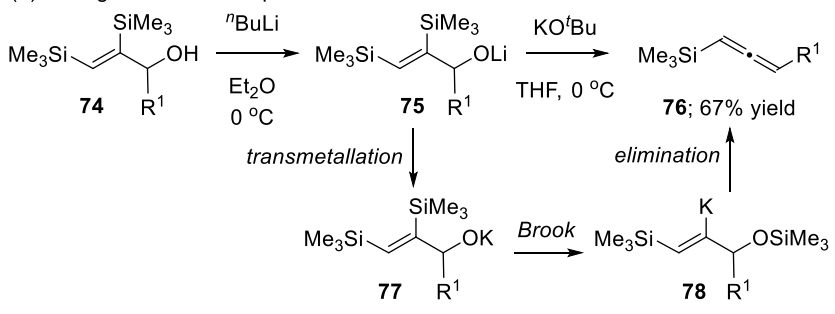

(c) Convert alcohol to a better leaving group

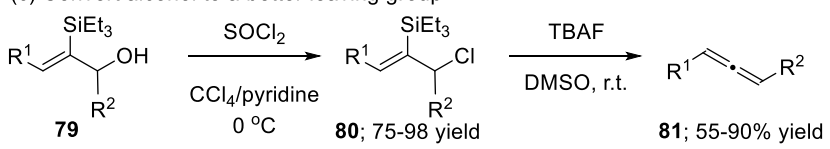

Scheme 19. Strategies for elimination of a $\beta$-silyl group

Larson, McGarvey and co-workers have reported the extension of the latter strategy to the asymmetric synthesis of allenes (Scheme 20). ${ }^{[43,44]}$ Vinyl bromide 82 bearing an enantiopure silyl group was treated with $t$-BuLi to effect lithium-halogen exchange followed by trapping with benzaldehyde. Allylic alcohol $\mathbf{8 3}$ was obtained as a 1:1 mixture of diastereoisomers which could be fully separated by column chromatography. Isolated 83a was then quantitatively transformed to the corresponding trifluoroacetate 84. Treatment with tris(dimethylamino)sulfonium difluorotrimethylsilicate (TASF) resulted in elimination to the corresponding allene 85 which was isolated in $50 \%$ yield. The stereospecificity of the allene forming step was very low but exhibited a small preference for an anti-elimination pathway.

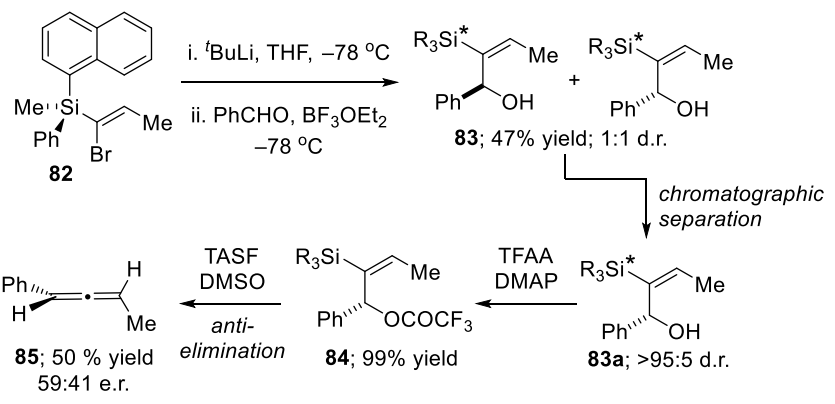

Scheme 20. Asymmetric synthesis of allenes by anti-elimination of a silyl group
Ito and co-workers have developed a synthesis of allenylsilanes by treatment of propargylic disilanes 86 with a palladium-tert-alkyl isocyanide complex followed by $n$-BuLi (Scheme 21). ${ }^{[45]}$ The process operates by initial palladium catalyzed intramolecular bis-silylation to generate four-membered intermediate 89. The $\mathrm{Si}-\mathrm{O}$ bond was then cleaved by $n$-BuLi to generate $\beta$-alkoxy silane 90. This intermediate underwent spontaneous syn-elimination to form allene 88 with very high enantiospecificity. Only one asymmetric example was reported, but a series of racemic allenes were also prepared using this method.

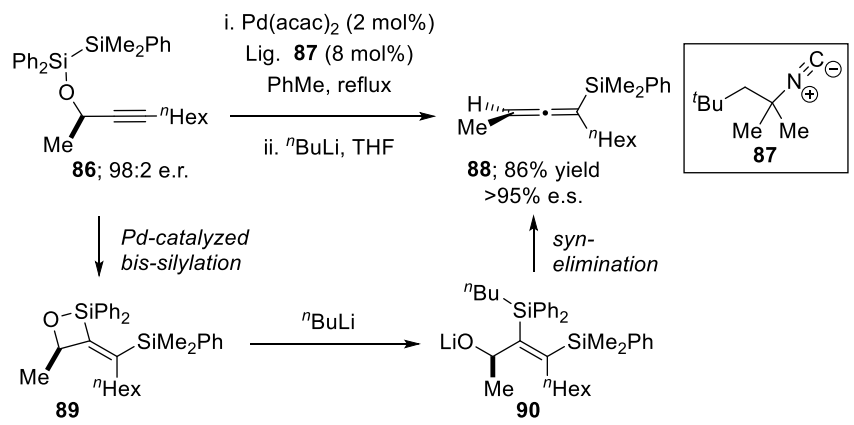

Scheme 21. Synthesis of chiral allenes by bis-silylation of alkynes followed by syn-elimination

Recently, Garg and Houk et al. disclosed an elegant method in which silyl triflates 91 were reacted with $\mathrm{CsF}$ to generate strained azacyclic allenes 92 (Scheme 22). ${ }^{[46]}$ These reactive intermediates were not isolated, but could be trapped by in situ cycloaddition to afford a wide range of racemic polycycles (for example rac-93a-c). Interestingly, when enantiopure silyl triflate precursors were employed, the cycloadduct products, such as (+)-93b were obtained with high levels of enantioenrichment. This implies that the elimination to form cyclic allenes is a stereospecific process. Several related processes in which strained cycloallenes are generated and reacted in situ have also been reported, but a full discussion of this work is outside the scope of this mini-review. ${ }^{[47]}$
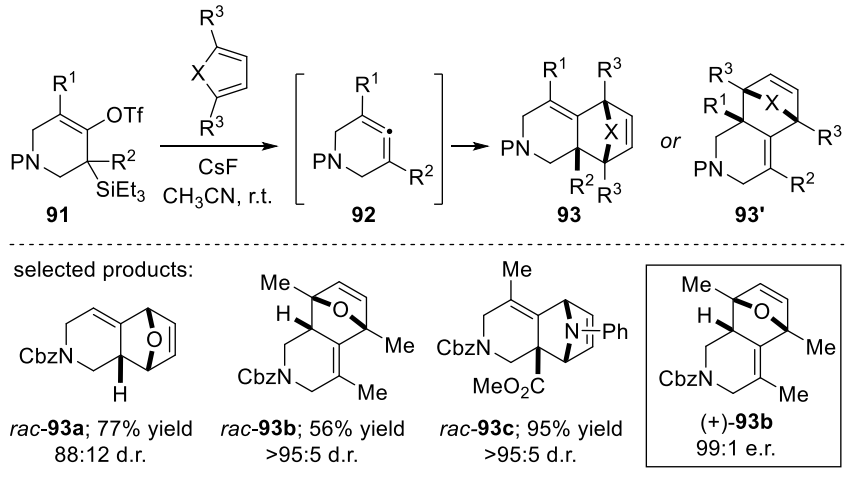

Scheme 22. 1,2-Elimination of cyclic silyl triflates

\subsection{Elimination of tin}

Konoike and Araki have shown that stannyl enone $\mathbf{9 4}$ can be reduced under CBS conditions with very high enantioselectivity (Scheme 23). ${ }^{[48]}$ The resulting secondary 
alcohol was converted to the corresponding acetate $\mathbf{9 5}$, which upon treatment with TBAF underwent enantiospecific anti-elimination affording allene 96 in $42 \%$ yield and 97:3 e.r.

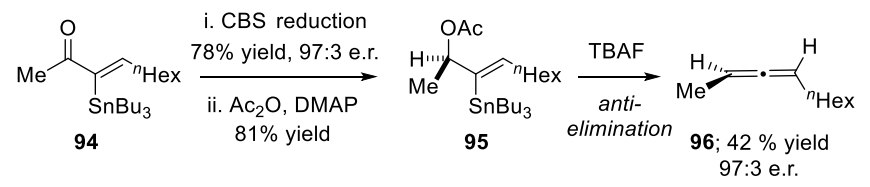

Scheme 23. Enantiospecific elimination of a vinyl stannane

Kitching and co-workers have applied a similar method to the asymmetric synthesis of $\Delta^{9,10}$-pentacosadiene (98), a natural product isolated from Australian Melolonthine scarab beetles (Scheme 24a). ${ }^{[49]}$ A similar strategy was also employed by Rigby et al. involving stereospecific elimination of vinyl mesylates en route to chiral bicyclo[4.2.1]nonanes such as $\mathbf{1 0 1}$ (Scheme 24b). ${ }^{[50]}$ Several other groups have reported related non-stereoselective 1,2elimination processes for the synthesis of aryl, ${ }^{[51]}$ alkyl, ${ }^{[52]}$ silyl, ${ }^{[53]}$ and methylenesilyl ${ }^{[54]}$ substituted allenes.

(a) Asymmetric synthesis of $\Delta^{9,10}$-pentacosadiene (98)

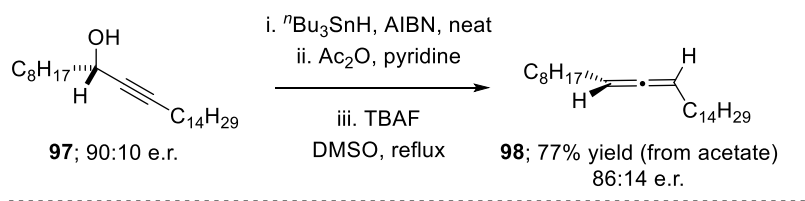

(b) Synthesis of enantioenriched bicyclo[4.2.1]nonane (101)

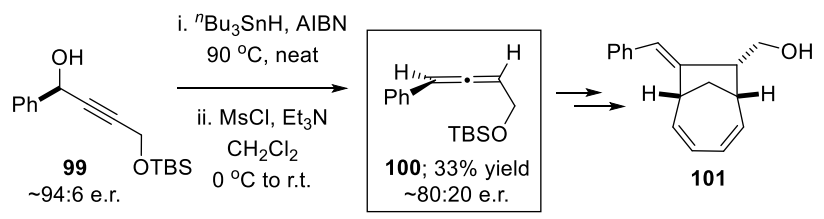

Scheme 24. Applications of enantiospecific vinyl stannane elimination in synthesis

\subsection{Elimination of boron}

Pelter et al. reported a bora-Wittig reaction for the synthesis of racemic allenes involving hydroboration of stannyl alkynes $\mathbf{1 0 2}$ followed by tin-lithium exchange, reaction with aldehydes and trifluoroacylation (Scheme 25). ${ }^{[55]}$ 1,2Elimination of the $\beta$-trifluoroacetoxy borane intermediates 104 occurred simply upon warming to room temperature which is likely a consequence of the strongly electron deficient nature of the borane functionality.

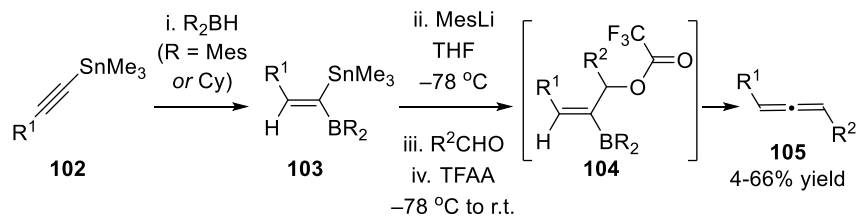

Scheme 25. Synthesis of allenes by a bora-Wittig reaction

Walsh and co-workers have developed an allenylation of vinyl boronic esters 106 bearing $\beta$-acetoxy or carbonate groups (Scheme 26). ${ }^{[56]}$ In the presence of catalytic $[\mathrm{Pd}(\text { allyl }) \mathrm{Cl}]_{2}$ and CyJohnPhos racemic allenes 107 were isolated in high yields. It was proposed that this reaction proceeds via $\beta$-elimination of a cationic $\pi$-allyl palladium intermediate 108. When a chiral non-racemic substrate 106a was employed, allene 107a produced at low conversion was enantioenriched (68:32 e.r.), but after the reaction reached completion, the allene product was found to be racemic. This suggests that the allenes formed in this process racemize under the reaction conditions. A similar process has also been reported involving vinyl stannanes - in this case the allenes produced were used in situ. ${ }^{[57]}$

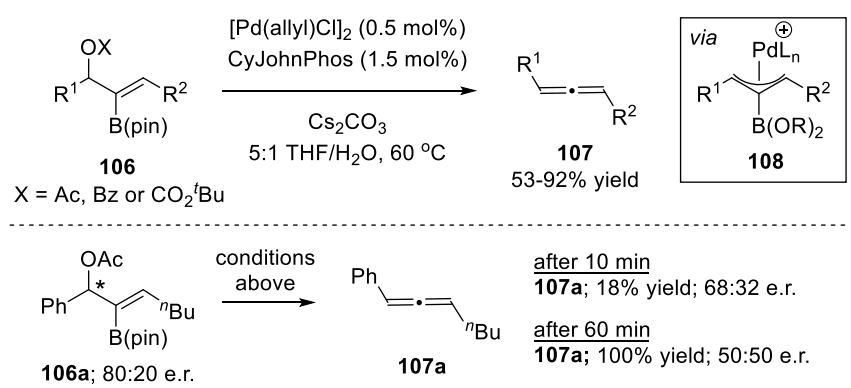

Scheme 26. Palladium catalyzed 1,2-elimination of vinyl boronic esters

Aggarwal and co-workers have recently reported an enantiodivergent strategy for the synthesis of chiral allenes (Scheme 27). ${ }^{[58]}$ In this work, $\alpha$-seleno alkenyl boronic esters 109 underwent one-carbon homologation with lithiated carbamates to afford highly enantioenriched $\beta$-selenoboronic esters 110. These intermediates could be oxidized with $m$-CPBA to the corresponding selenoxides which underwent syn-elimination (see TS-syn), ${ }^{[59]}$ forming allenes 111 with very high levels of enantiospecificity. Alternatively, methylation of intermediate $\mathbf{1 1 0}$ followed by addition of sodium bicarbonate enabled stereospecific anti-elimination affording the opposite enantiomer of the allene products (see TS-anti). In this way, either enantiomer of an axially chiral allene could be obtained from a single point-chiral precursor. The reaction could be used to synthesize di-, tri- and tetrasubstituted allenes (for example 111a-111c).
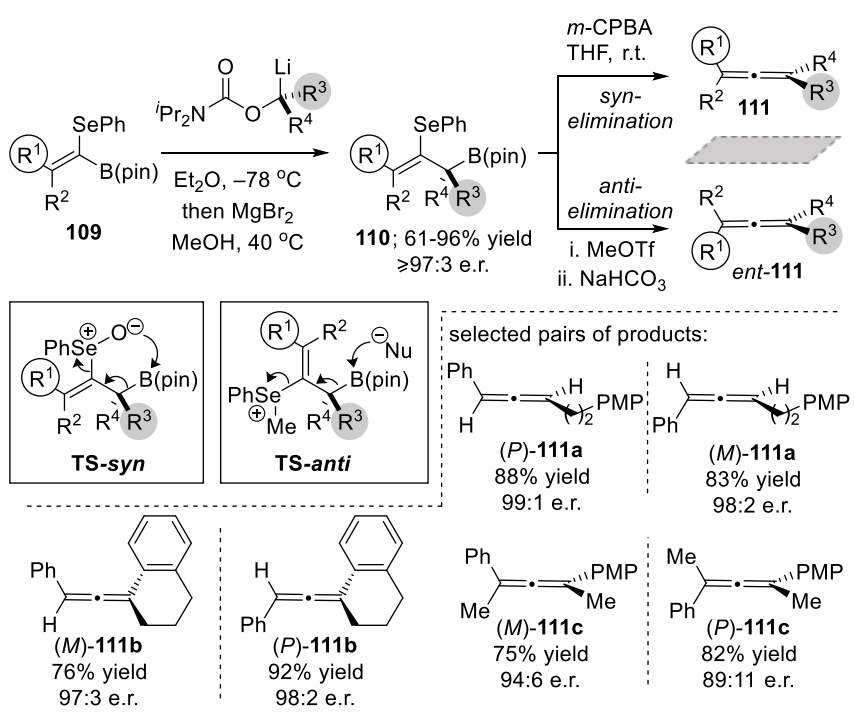

Scheme 27. Enantiodivergent synthesis of allenes by syn- or anti-elimination of vinyl boronic esters 


\subsection{Elimination of titanium}

Takeda and co-workers have developed an allenylation process between 1,1-dichloroalkenes $\mathbf{1 1 2}$ and ketones mediated by a low valent titanocene complex (Scheme 28). ${ }^{\left[{ }^{60]}\right.}$ Mechanistically, it was proposed that this reaction occurs by reduction of dichloride 112 with two equivalents of $\mathrm{Cp}_{2} \mathrm{Ti}\left[\mathrm{P}(\mathrm{OEt})_{3}\right]_{2}$ leading to titanium vinylidene 114. This intermediate then reacted with ketones to generate oxatitanacyclobutanes $\mathbf{1 1 5}$ which finally underwent 1,2-elimination to form allenes. A range of tetrasubstituted allenes were synthesized (for example 113a113c) in good yields. Related allenylation processes have also been reported in which titanium vinylidenes (e.g. 114) are generated by metathesis, ${ }^{[61]}$ carbometalation, ${ }^{[62]}$ $\alpha$-elimination, ${ }^{[63]}$ and cycloaddition. ${ }^{[64]}$

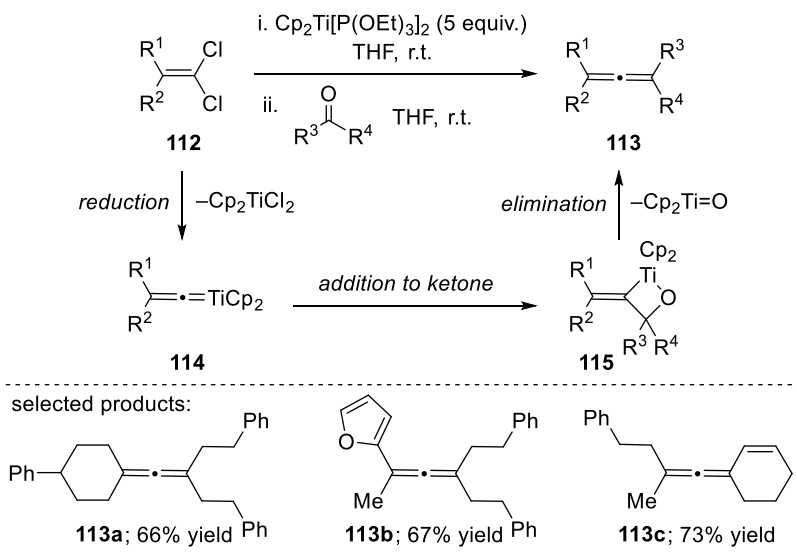

Scheme 28. $\mathrm{Cp}_{2} \mathrm{Ti}\left[\mathrm{P}(\mathrm{OEt})_{3}\right]_{2}$ mediated synthesis of allenes

\subsection{Elimination of zirconium}

A pioneering example involving elimination of vinyl zirconium intermediates was reported by Knochel and coworkers (Scheme 29). ${ }^{[65]}$ Alkynyl zinc halides 116 were hydrozirconated with the Schwartz reagent to generate 1,1,dimetalloalkenes $\mathbf{1 1 7}$ which could be reacted with aldehydes to afford racemic allenes $\mathbf{1 1 9}$ via a 1,2-elimination mechanism. A related process has also been reported with gallium-containing bimetallics. ${ }^{[66]}$

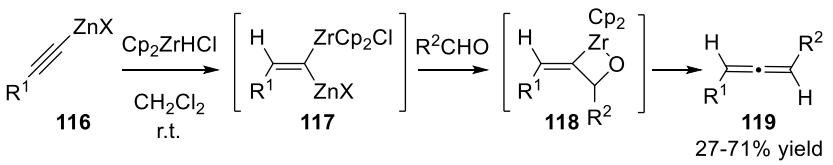

Scheme 29. Synthesis of racemic allenes by a hydrozirconation-elimination approach

Ready and co-workers have reported that enantiopure propargylic alcohols $\mathbf{1 2 0}$ could be deprotonated to form the corresponding zinc or magnesium alkoxides $\mathbf{1 2 1}$ and then hydrozirconated with the Schwartz reagent with complete control over regiochemistry (Scheme 30). ${ }^{[67]}$ The resulting vinyl zirconium intermediates $\mathbf{1 2 2}$ then underwent spontaneous syn-elimination affording allenes $\mathbf{1 2 3}$ with very high levels of enantiospecificity. A series of enantioenriched disubstituted allenes (e.g. 123a-123c) were synthesized using this methodology in excellent yields and with up to 99:1 e.r. It is noteworthy that overall this method represents a nucleophilic addition reaction to a propargylic electrophile (see Scheme 1, route a) and other related examples involving stepwise addition-elimination are not discussed in this minireview.

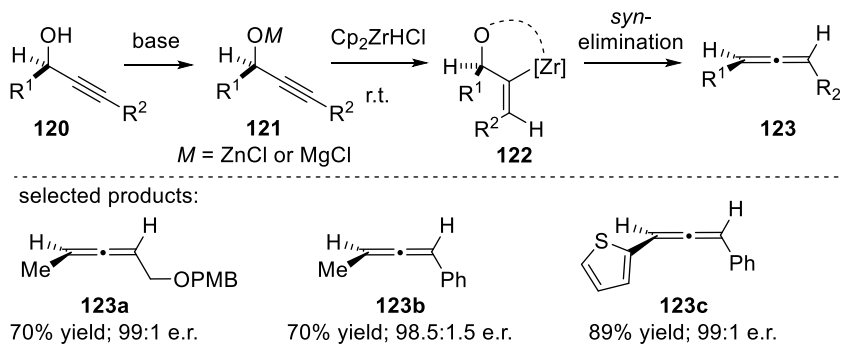

Scheme 30. Enantiospecific synthesis of allenes by 1,2elimination of vinyl zirconium intermediates

\subsection{Elimination of magnesium}

Satoh and co-workers have reported a series of elegant processes involving alkenylation of magnesium carbenoids. For example, it was shown that 1-chlorovinyl sulfoxides $\mathbf{1 2 4}$ could undergo magnesium-sulfoxide exchange with EtMgCl (in the presence of $t-\mathrm{BuMgCl}$ as an unusual desiccant) to form magnesium carbenoids $\mathbf{1 2 5}$ (Scheme 31). ${ }^{[68]}$ Subsequent addition of lithiated sulfone $\mathbf{1 2 6}$ resulted in substitution to generate intermediate $\mathbf{1 2 7}$ which underwent spontaneous 1,2-elimination to afford allene products such as 128a-c. The Satoh group have subsequently expanded this methodology to the synthesis of racemic allenes substituted with esters, ${ }^{[69]}$ unsaturated esters, ${ }^{[70]}$ and vinyl groups. ${ }^{[71]}$ This work has been recently reviewed by Zhang, Xi and coworkers. ${ }^{[72]}$

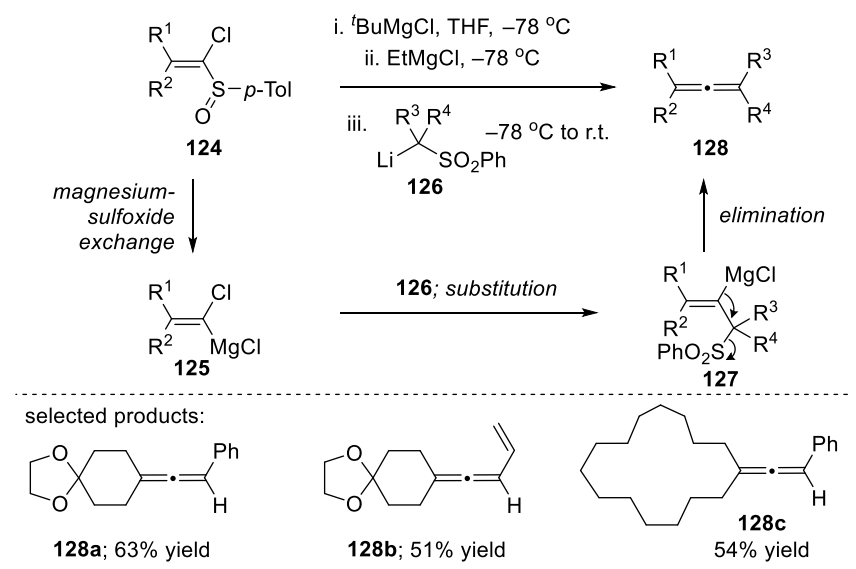

Scheme 31. Synthesis of allenes by alkenylation of magnesium carbenoids

Satoh and co-workers have also reported an asymmetric synthesis of allenes such as $\mathbf{1 3 1}$ (a sex attractant of the male bean weevil) relying on magnesium-sulfoxide exchange (Scheme 32). ${ }^{[73]}$ Enantioenriched vinyl sulfoxide 129 was lithiated with LDA and then trapped with an aldehyde to generate a diastereoisomeric mixture of the corresponding allylic alcohols. Reaction with $\mathrm{Ac}_{2} \mathrm{O}$ afforded diastereomeric acetates 130a and 130b which could be separated by column 
chromatography. Treatment of either 130a or $130 \mathrm{~b}$ with $i$ $\mathrm{PrMgCl}$ resulted in magnesium-sulfoxide exchange followed by anti-elimination to generate enantiomeric allenes $(M)$-131 or $(P)$-131 with high levels of enantiospecificity.

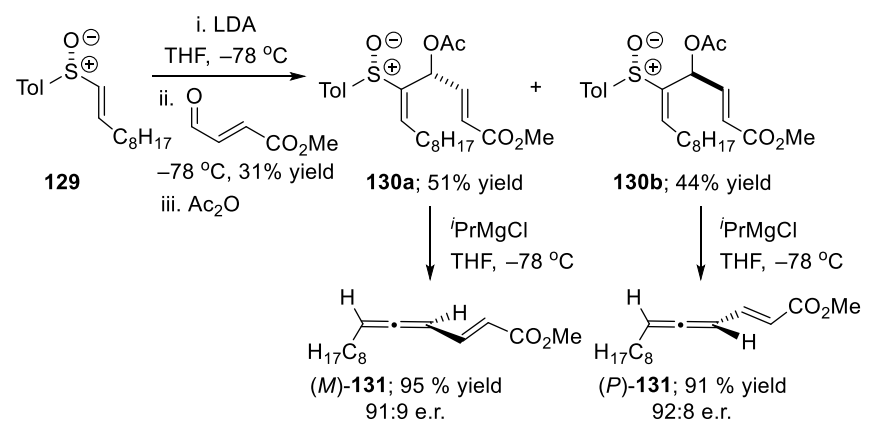

Scheme 32. Asymmetric synthesis of allenes by magnesiumsulfoxide exchange

$\mathrm{Wu}$ and co-workers have applied this methodology to a formal synthesis of the antibiotic (+)-scorodonin (Scheme 33a). ${ }^{[74]}$ In this case, vinyl sulfoxide 132 underwent magnesium sulfoxide exchange followed by anti-elimination to afford allene $\mathbf{1 3 3}$ in $80 \%$ yield with high enantiospecificity. It had previously been reported that this intermediate could be converted to scorodonin in three steps. The $\mathrm{Wu}$ group have also devised a related approach to bioactive natural allenes such as $\mathbf{1 3 5}$ via magnesium-iodine exchange followed by anti-elimination (Scheme 33b). ${ }^{[75]} \mathrm{A}$ similar synthesis of the natural antibiotic (-)-marasin has been reported from vinyl iodide 136 (Scheme 33c). ${ }^{[76]}$ Stereospecific anti-elimination with $i-\mathrm{PrMgBr}$ followed by acid mediated TBS deprotection delivered (-)-marasin in $79 \%$ yield and $87.5: 12.5$ e.r.

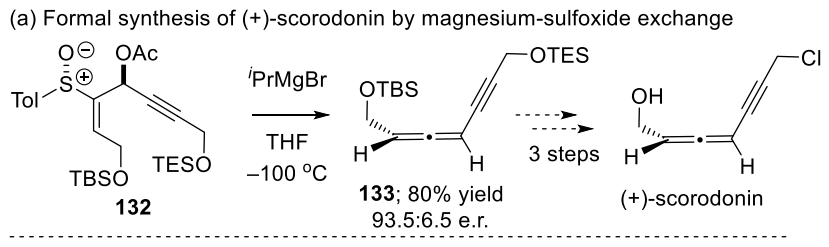

(b) Asymmetric synthesis of bioactive natural allene 135

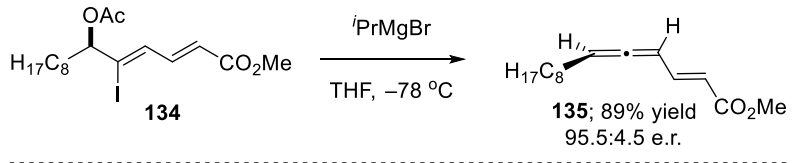

(c) Synthesis of (-)-marasin by magnesium-halogen exchange

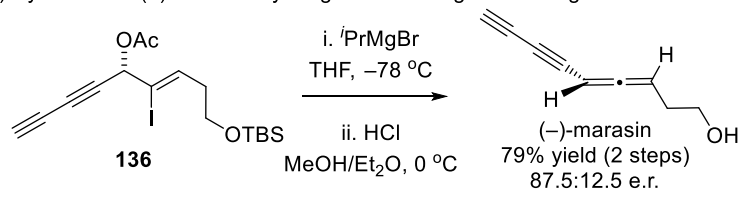

Scheme 33. Applications of 1,2-elimnation of vinyl magnesium intermediates in synthesis

\subsection{Elimination of lithium}

Several non-stereoselective elimination processes involving reduction with lithium or organolithiums have also been reported. ${ }^{[77]}$ For example, Barluenga et al. have reported that chlorinated allylic alcohols 137 can be transformed to racemic allenes by $O$-methylation followed by reduction with lithium powder (Scheme 34a). ${ }^{[78]}$ More recently, Ichikawa and co-workers reported a sequence involving addition of 1-bromo-2,2-difluorovinyllithium to carbonyl substrates at $-100{ }^{\circ} \mathrm{C}$ followed by acylation to afford allylic acetates 140 (Scheme 34b). ${ }^{[79]}$ Lithium-halogen exchange followed by elimination generated 1,1-difluoroallenes $\mathbf{1 4 1}$ in good to excellent yields. Unlike the corresponding reactions involving vinyl magnesium intermediates (vide supra) this chemistry has not been widely applied to asymmetric allene synthesis.

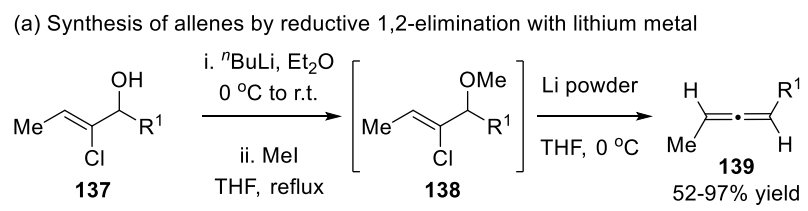

(b) Synthesis of 1,1-difluoroallenes

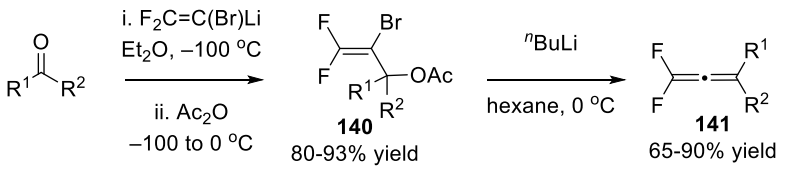

Scheme 34. Selected examples of non-stereoselective formation of allenes by 1,2-elimination of organolithiums

\subsection{Elimination of zinc}

Ichikawa and co-workers have devised an improved method for the synthesis of 1,1-difluoroallenes (Scheme 35a). ${ }^{[80]}$ Iodine containing allylic acetates $\mathbf{1 4 2}$ were synthesized from commercially available 1,1,1-trifluoro-2-iodoethane and were converted to allenes in good to excellent yields by reduction with zinc powder. The 1,1-difluoroallene products are useful compounds, which have been employed in the synthesis of polycyclic aromatic hydrocarbons. ${ }^{[81]}$ A related method for the synthesis of trifluoromethyl allenes was introduced by Yamazaki et al. ${ }^{[82,83]}$ and later developed by Krische and co-workers ${ }^{[84]}$ (Scheme 35b). In this work, dibromides 145 were synthesized by an in situ Finkelstein reaction and then efficiently converted to allenes by reduction with zinc dust. Lin et al. have reported that terminal allenes 148 can be obtained in high yields by reduction of vicinal dihalides 147 with zinc or indium (Scheme 35c). ${ }^{[85]}$
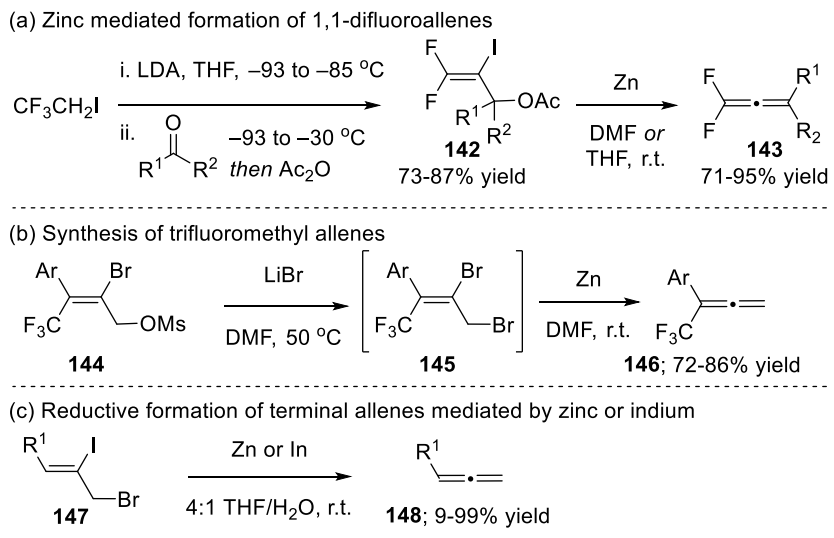

Scheme 35. Formation of allenes by reduction with zinc 
Marek and co-workers have reported an asymmetric allene synthesis involving carbocupration of enantiopure ethynyl sulfoxide 149 followed by treatment with a zinc carbenoid (Scheme 36). ${ }^{[86]}$ Mechanistically, it is thought that this process operates by one carbon homologation of $\mathbf{1 5 0}$ to form allylic zinc species $\mathbf{1 5 2}$ as a mixture of diastereoisomers which can equilibrate to the thermodynamically preferred isomer 152a. Syn-elimination then delivered the allene product in $75 \%$ yield with good enantioselectivity. Only one asymmetric example was reported, but several racemic allenes were also prepared using this method.

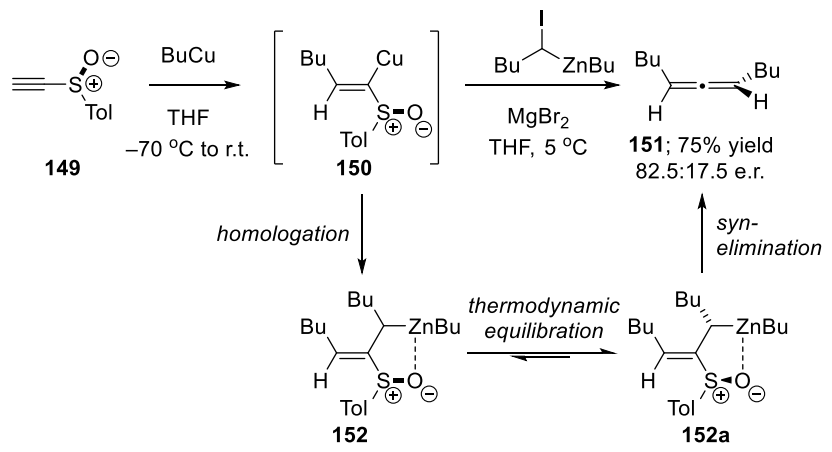

Scheme 36. Asymmetric synthesis of allenes by one carbon homologation followed by syn-elimination

\subsection{Elimination of palladium}

Tanaka and co-workers have developed a synthesis of allenes in which vicinal bromomesylates 153 were reduced with diethylzinc in the presence of a catalytic amount of $\mathrm{Pd}\left(\mathrm{PPh}_{3}\right)_{4}$ (Scheme 37). ${ }^{[87]}$ Mechanistically, it was proposed that this reaction occurs by oxidative elimination to form $\pi$-allyl palladium intermediates $\mathbf{1 5 5}$ or $\mathbf{1 5 6}$, which could undergo 1,2-elimination to form allenes. The palladium(II) by-product was then recycled by reduction with diethylzinc. A series of terminal allenes were prepared in good yields (e.g. 154a and 154b). With diastereomerically pure mesylate $153 \mathbf{c}$, allene $154 \mathbf{c}$ was isolated in $86 \%$ yield as a mixture of diastereomers, implying that the elimination process is nonstereospecific. ${ }^{[88]}$ Related processes involving nickel, ${ }^{[89]}$ copper ${ }^{[90]}$ and stoichiometric palladium ${ }^{[91]}$ mediated reduction have also been reported.

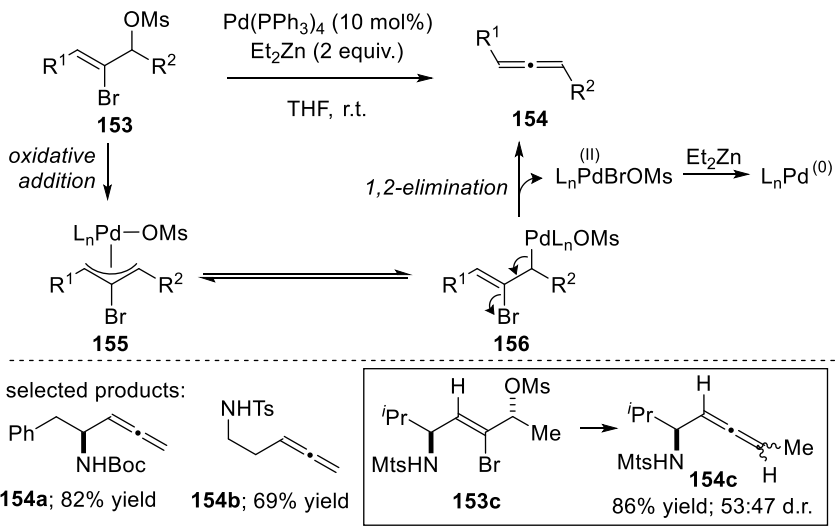

Scheme 37. Allene synthesis via palladium mediated elimination

\subsection{Elimination of carbon}

Danheiser and co-workers have developed a method for the synthesis of racemic allenes involving a thermal cycloreversion of $\alpha$-alkylidene- $\beta$-lactones (Scheme 38). ${ }^{[92]}$ Substrates 159 were synthesized by a multi-step route involving phenylselenylation of $\beta$-lactones $\mathbf{1 5 7}$ followed by oxidation and selenoxide elimination. Upon heating to $>110^{\circ} \mathrm{C}$ these intermediates underwent decarboxylation to generate racemic allenes $\mathbf{1 6 0}$ in good to excellent yields. This method has also been applied to the synthesis of sily ${ }^{[93]}$ and aryl ${ }^{[94]}$ substituted allenes.

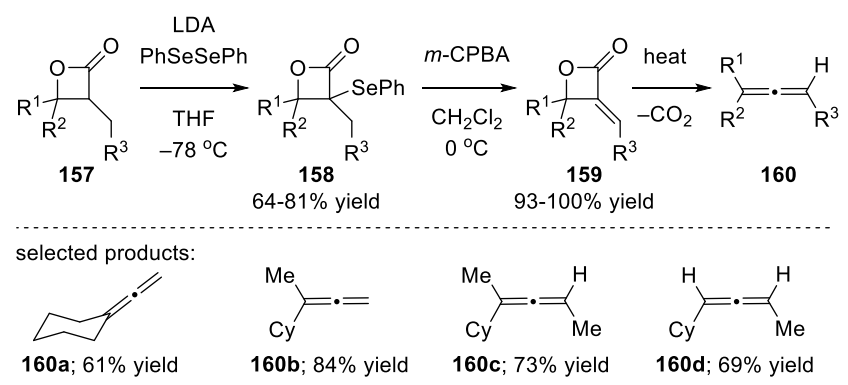

Scheme 38. Synthesis of allenes by thermal cycloreversion of $\alpha$-alkylidene- $\beta$-lactones

Williams and co-workers have reported a synthesis of allenes from cyclic keto-triflate 161. ${ }^{[95]}$ It was demonstrated that a series of nucleophiles (for example organolithium reagents, Grignards and enolates) could add to the ketone followed by spontaneous Grob fragmentation to deliver allenes $\mathbf{1 6 2}$ (Scheme 39a). Moreover, it was also demonstrated that enantiopure silyl ethers such as 163a could be treated with TBAF, resulting in $\mathrm{C}-\mathrm{C}$ fragmentation to form aldehydes, which were reduced in situ with $\mathrm{NaBH}_{4}$ (Scheme 39b). Isomeric substrates 163a and $163 \mathrm{~b}$ were cleanly converted to enantiomeric allenes $(P)-164$ and $(M)$-164, thereby demonstrating that the fragmentation process proceeds via stereospecific anti-elimination.

(a) Synthesis of allenes by nucleophilic addition followed by Grob fragmentation

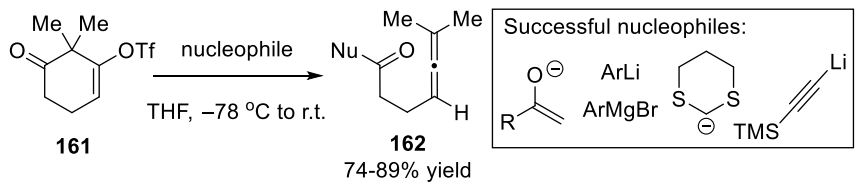

(b) Extension to enantiospecific elimination

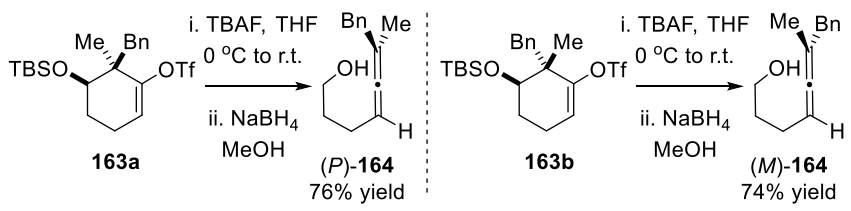

Scheme 39. Synthesis of allenes by stereospecific Grob fragmentation

Cramer and Saget have reported a related method in which cyclic keto-triflates 165 were treated with heteroatom based nucleophiles resulting in the formation of allenes 166 in excellent yields (Scheme 40). ${ }^{[96]}$ An extensive range of 
products were prepared including esters, carboxylic acids and amides. The allene products produced in these reactions were also employed in a series of in situ functionalization processes.

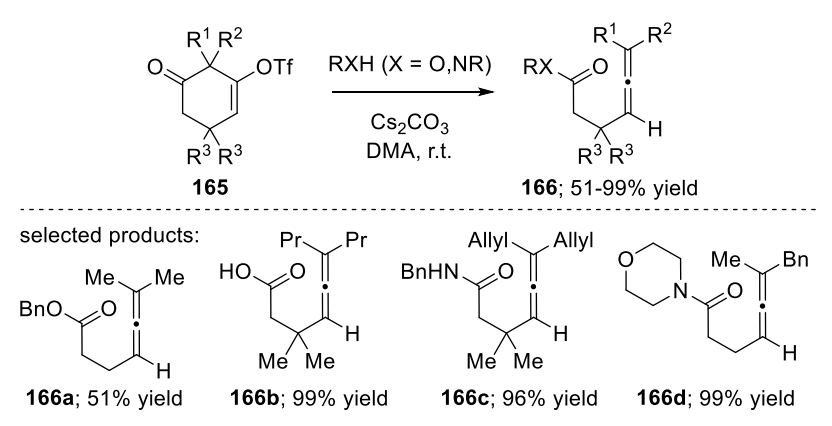

Scheme 40. Synthesis of allenes by $\mathrm{C}-\mathrm{C}$ cleavage

\subsection{Elimination of radicals}

Fensterbank, Malacria and co-workers have reported that $\beta$ bromosulfoxides 167 can be converted to terminal allenes 168 upon treatment with tris(trimethylsilyl)silane and AIBN (Scheme 41). ${ }^{[97]}$ It was proposed that this process operates via formation of an allylic radical 169, which can undergo $\beta$-elimination to form allene products. Both mono- and disubstituted allenes could be obtained using this method in moderate to good yields. The method has also been extended to synthesis of trifluoromethylallenes. ${ }^{[98]}$

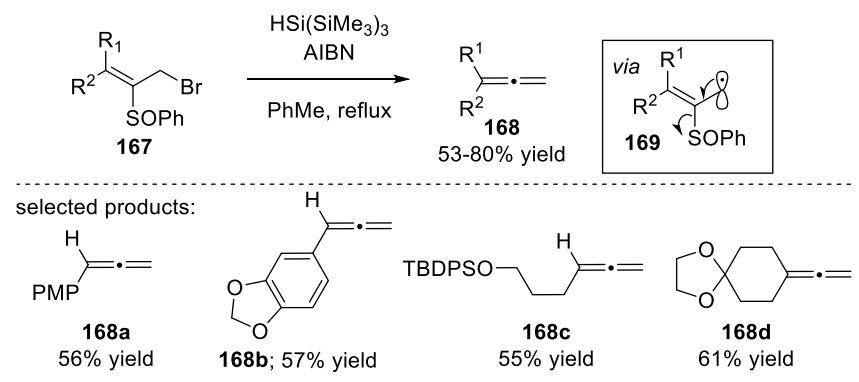

Scheme 41. Synthesis of mono- and di-substituted allenes via elimination of $\beta$-sulfoxy radicals

\section{CONCLUSION}

This mini-review presents a range of 1,2-elimination methods for the preparation of allenes involving chemistry from across the periodic table. Examples of methods targeting mono-, di- triand tetrasubstituted allenes are presented including eliminations which proceed via both radical and polar mechanisms. By precisely controlling the nature of the elimination process (syn or anti) it is often possible to achieve very high levels of control over the axial chirality of the allene products. Although modern synthetic methods for allene synthesis are generally dominated by methods involving propargylic substitution processes, 1,2elimination can provide an efficient alternative for allene synthesis and it is anticipated that this chemistry will have exciting applications in materials science, catalysis and medicinal chemistry.

\section{CONFLICT OF INTEREST}

The author declares no conflict of interest.

\section{ACKNOWLEDGEMENTS}

R.J.A. thanks University College, Oxford for financial support and Prof. Varinder Aggarwal FRS, Prof. Timothy Donohoe, Prof. Martin Smith and Dr Hamish Hepburn for helpful discussions during the preparation of this manuscript.

\section{REFERENCES}

[1] (a) Modern Allene Chemistry; Krause, N., Hashmi, A. S. K., Eds.; Wiley-VCH: Weinheim, Germany, 2004. (b) Hoffmann-Röder, A.; Krause, N. Synthesis and Properties of Allenic Natural Products and Pharmaceuticals. Angew. Chem. Int. Ed. 2004, 43 (10), 1196-1216. (c) Cooper, G. F.; Wren, D. L.; Jackson, D. Y.; Beard, C. C.; Galeazzi, E.; Van Horn, A. R.; Li, T. T. J. Org. Chem. 1993, 58 (16), 4280-4286. (d) Yu, L.; Wang, H.; Akhmedov, N.; Williams, L. J. J. Antibiot. 2019, 72 (6), 432-436. (e) Ban, H. S.; Onagi, S.; Uno, M.; Nabeyama, W.; Nakamura, H. Chem. Med. Chem. 2008, 3 (7), 1094-1103. (f) Rivera-Fuentes, P.; Diederich, F. Allenes in Molecular Materials. Angew. Chem. Int. Ed. 2012, 51 (12), 2818-2828. (g) Kino, T.; Taguchi, M.; Tazawa, A.; Tomita, I. Macromolecules 2006, 39 (22), 7474-7478.

[2] For a review, see: (a) Krause, N.; Hoffmann-Röder, A. Synthesis of Allenes with Organometallic Reagents. Tetrahedron 2004, 60 (51), 11671-11694. For selected examples, see: (b) Yang, M.; Yokokawa, N.; Ohmiya, H.; Sawamura, M. Synthesis of Conjugated Allenes through Copper-Catalyzed $\gamma$-Selective and Stereospecific Coupling between Propargylic Phosphates and Aryl- or Alkenylboronates. Org. Lett. 2012, 14 (3), 816-819. (c) Partridge, B. M.; Chausset-Boissarie, L.; Burns, M.; Pulis, A. P.; Aggarwal, V. K. Enantioselective Synthesis and Cross-Coupling of Tertiary Propargylic Boronic Esters Using Lithiation-Borylation of Propargylic Carbamates. Angew. Chem. Int. Ed. 2012, 51 (47), 11795-11799.

[3] Yanpeng Xing; Yuxiu Wei and Hongwei Zhou. Applications of the in Situ Propargyl-Allenyl Isomerization in Organic Synthesis. Curr. Org. Chem. 2012, 16 (13), 1594-1608.

[4] (a) Hossain, M. L.; Wang, J. Cu(I)-Catalyzed Cross-Coupling of Diazo Compounds with Terminal Alkynes: An Efficient Access to Allenes. Chem. Rec. 2018, 18 (11), 1548-1559. (b) Chu, W.-D.; Zhang, L.; Zhang, Z.; Zhou, Q.; Mo, F.; Zhang, Y.; Wang, J. Enantioselective Synthesis of Trisubstituted Allenes via Cu(I)-Catalyzed Coupling of Diazoalkanes with Terminal Alkynes. J. Am. Chem. Soc. 2016, 138 (44), 14558-14561.

[5] (a) Tejedor, D.; Méndez-Abt, G.; Cotos, L.; García-Tellado, F. Propargyl Claisen Rearrangement: Allene Synthesis and Beyond. Chem. Soc. Rev. 2012, 42 (2), 458-471. (b) Myers, A. G.; Zheng, B. New and Stereospecific Synthesis of Allenes in a Single Step from Propargylic Alcohols. J. Am. Chem. Soc. 1996, 118 (18), 4492-4493. (c) Tang, X.; Zhu, C.; Cao, T.; Kuang, J.; Lin, W.; Ni, S.; Zhang, J.; Ma, S. Cadmium Iodide-Mediated Allenylation of Terminal Alkynes with Ketones. Nature Commun. 2013, 4, 2450.

[6] (a) Brummond, K. M.; DeForrest, J. E. Synthesizing Allenes Today (1982-2006). Synthesis 2007, 6, 795-818. (b) Yu, S.; Ma, S. How Easy Are the Syntheses of Allenes? Chem. Commun. 2011, 47 (19), 5384 5418. (c) Neff, R. K.; Frantz, D. E. Recent Advances in the Catalytic Syntheses of Allenes: A Critical Assessment. ACS Catal. 2014, 4 (2), 519-528. (d) Ye, J.; Ma, S. Conquering Three-Carbon Axial Chirality of Allenes. Org. Chem. Front. 2014, 1 (10), 1210-1224. (e) Chu, W.D.; Zhang, Y.; Wang, J. Recent Advances in Catalytic Asymmetric Synthesis of Allenes. Catal. Sci. Technol. 2017, 7 (20), 4570-4579.

[7] For selected examples, see: (a) Pillot, J.-P.; Bennetau, B.; Dunogues, J.; Calas, R. Nouvelle Voie d'acces Aux Cetones $\alpha$-Alleniques. Tetrahedron Lett. 1981, 22 (35), 3401-3404. (b) Stang, P. J.; Hargrove, R. J. Vinyl Triflates in Synthesis. II. 1,1-Di-, Tri-, Tetrasubstituted and Deuterio Allenes from Ketones via Vinyl Triflates. J. Org. Chem. 1975, 40 (5), 657-658. (c) Witt, O.; Mauser, H.; Friedl, T.; Wilhelm, D.; Clark, T. Reactions of the Lithium Salts of the Tribenzylidenemethane Dianion, Diphenylacetone Dianion, and Related Compounds. J. Org. Chem. 1998, 63 (4), 959-967. (d) Langer, P.; Döring, M.; Seyferth, D.; Görls, H. Direct Transformation of Silyl Enol Ethers into Functionalized Allenes. Chem. Eur. J. 2001, 7 (3), 573-584.

[8] Brummond, K. M.; Dingess, E. A.; Kent, J. L. Strategy for the Preparation of Allenes from $\alpha, \beta$-Unsaturated and Saturated Ketones via Enol Phosphates. J. Org. Chem. 1996, 61 (18), 6096-6097. 
[9] For selected examples, see: (a) Buono, G. A New Convenient Synthesis of 1,2-Pentadien-4-One (Acetylallene). Synthesis 1981, 11, 872-872. (b) Ma, S.; Li, L.; Xie, H. Hydrohalogenation Reaction of 1,2-Allenyl Ketones Revisited. Efficient and Highly Stereoselective Synthesis of $\beta, \gamma$-Unsaturated $\beta$-Haloketones. J. Org. Chem. 1999, 64 (14), 5325-5328. (c) Ma, S.; Yu, S.; Yin, S. Studies on $\mathrm{K}_{2} \mathrm{CO}_{3}-$ Catalyzed 1,4-Addition of 1,2-Allenic Ketones with Diethyl Malonate: Controlled Selective Synthesis of $\beta, \gamma$-Unsaturated Enones and $\alpha$-Pyrones. J. Org. Chem. 2003, 68 (23), 8996-9002.

[10] Kim, H. Y.; Li, J.-Y.; Oh, K. Studies on Elimination Pathways of $\beta-$ Halovinyl Ketones Leading to Allenyl and Propargyl Ketones and Furans under the Action of Mild Bases. J. Org. Chem. 2012, 77 (24), 11132-11145.

[11] (a) Komatsu, N.; Nishibayashi, Y.; Sugita, T.; Uemura, S. The First Example of Asymmetric Selenoxide Elimination: Application to the Synthesis of Chiral Allenes. J. Chem. Soc., Chem. Commun. 1992, 4647. (b) Komatsu, N.; Murakami, T.; Nishibayashi, Y.; Sugita, T.; Uemura, S. Asymmetric Selenoxide Elimination Leading to Chiral Allenic Sulfones. J. Org. Chem. 1993, 58 (14), 3697-3702.

[12] (a) Nishibayashi, Y.; Deo Singh, J.; Uemura, S.; Fukuzawa, S. Synthesis of Chiral Diferrocenyl Diselenides and Their Application to Asymmetric Reactions. Tetrahedron Lett. 1994, 35 (19), 3115-3118. (b) Nishibayashi, Y.; Singh, J. D.; Fukuzawa, S.; Uemura, S. Synthesis of $\quad[R, S ; R, S]-\quad$ and $\quad[S, R ; S, R]$-Bis[2-[1(Dimethylamino)Ethyl]Ferrocenyl] Diselenides and Their Application to Asymmetric Selenoxide Elimination and [2,3]Sigmatropic Rearrangement. J. Org. Chem. 1995, 60 (13), 4114-4120.

[13] Honda, M.; Nishizawa, T.; Nishii, Y.; Fujinami, S.; Segi, M. Reaction Behavior of Cyclopropylmethyl Cations Derived 1Phenylselenocyclopropylmethanols with Acids. Tetrahedron 2009, 65 (45), 9403-9411.

[14] Crouch, I. T.; Neff, R. K.; Frantz, D. E. Pd-Catalyzed Asymmetric $\beta$ Hydride Elimination En Route to Chiral Allenes. J. Am. Chem. Soc. 2013, 135 (13), 4970-4973.

[15] El Arba, M.; Dibrell, S. E.; Crouch, I. T.; Frantz, D. E. Unified Approach to Substituted Allenoates via Pd-Catalyzed $\beta$-Hydride Elimination of (E)-Enol Triflates. Org. Lett. 2017, 19 (19), 5446-5449.

[16] For earlier examples of allene formation by Heck processes, see: (a) Tao, W.; Silverberg, L. J.; Rheingold, A. L.; Heck, R. F. Alkyne Reactions with Arylpalladium Compounds. Organometallics 1989, 8 (11), 2550-2559. (b) Pivsa-Art, S.; Satoh, T.; Miura, M.; Nomura, M. Palladium-Catalyzed Reaction of Aryl Bromides with Dialkylacetylenes to Produce Allenic Compounds. Chem. Lett. 1997, 26 (8), 823-824. (c) Chapman, L. M.; Adams, B.; Kliman, L. T.; Makriyannis, A.; Hamblett, C. L. Intramolecular Heck Reactions of Aryl Chlorides with Alkynes. Tetrahedron Lett. 2010, 51 (11), 15171522.

[17] Nella, N.; Parker, E.; Hitce, J.; Larini, P.; Jazzar, R.; Baudoin, O. Efficient Pd-Catalyzed Allene Synthesis from Alkynes and Aryl Bromides through an Intramolecular Base-Assisted Deprotonation (IBAD) Mechanism. Chem. Eur. J. 2014, 20 (41), 13272-13278.

[18] Neff, R. K.; Frantz, D. E. Cationic Alkynyl Heck Reaction toward Substituted Allenes Using BobCat: A New Hybrid Pd(0)-Catalyst Incorporating a Water-Soluble dba Ligand. J. Am. Chem. Soc. 2018, $140(50), 17428-17432$

[19] (a) Liu, B.; Wang, K. K.; Petersen, J. L. Synthesis of (4Z)-1,1Diphenyl-1,2,4-Heptatrien-6-Ynes and Their Facile Cycloaromatizations to $\alpha, 3$-Didehydrotoluene Biradicals Having a Triarylmethyl Radical Center. J. Org. Chem. 1996, 61 (24), 85038507. (b) Wang, K. K.; Zhang, H.-R.; Petersen, J. L. Thermolysis of Benzoenyne-Allenes To Form Biradicals and Subsequent Intramolecular Trapping with a Tetraarylallene To Generate Two Triarylmethyl Radical Centers. J. Org. Chem. 1999, 64 (5), 16501656.

[20] (a) Inoue, H.; Tsubouchi, H.; Nagaoka, Y.; Tomioka, K. Synthesis of Allenes by Double Horner-Wadsworth-Emmons Reaction. Tetrahedron 2002, 58 (1), 83-90. (b) Nagaoka, Y.; Tomioka, K. Baylis-Hillman-Type Carbon-Carbon Bond Formation of Alkenylphosphonates by the Action of Lithium Diisopropylamide. $J$. Org. Chem. 1998, 63 (19), 6428-6429.

[21] For an early example, see: Hirama, M. Regioselective Conjugate Addition of Sulfonylallyl Carbanions to $\alpha$, $\beta$-Unsaturated Ketones. Tetrahedron Lett. 1981, 22 (20), 1905-1908.

[22] Huang, X.; Xiong, Z.-C. Facile Synthesis of Sulfur-Substituted Allenes by a Three-Component Reaction. Tetrahedron Lett. 2003, 44 (31), $5913-5915$
[23] Huang, X.; Xiong, Z.-C. A Novel One-Pot Three-Component Tandem Michael/Aldol/Horner-Wadsworth-Emmons (HWE) Reaction of Lithium Alkylselenolates with 1-Alkynylphosphine Oxides and Aldehydes: Facile Synthesis of Selenium-Substituted Allenes. Chem. Commun. 2003, 14, 1714-1715.

[24] Xi, Z.; Zhang, W.-X.; Song, Z.; Zheng, W.; Kong, F.; Takahashi, T. Preparation of Vinyl Allenes from 1-Lithio-1,3-Dienyl Phosphine Oxides and Aldehydes by the Wittig-Horner Reaction. J. Org. Chem. 2005, 70 (22), 8785-8789.

[25] Reynolds, K. A.; Dopico, P. G.; Brody, M. S.; Finn, M. G. Vinylphosphonium Salts and Allenes from Carbonyl Compounds Using Titanium-Substituted Ylides. J. Org. Chem. 1997, 62 (8), 2564 2573.

[26] Jiang, H.; Wang, W.; Yin, B.; Liu, W. Facile Synthesis of Trisubstituted Allenynes by Phosphane-Mediated Deoxygenation of 2,4-Pentadiyn-1-Ol. Eur. J. Org. Chem. 2010, 2010 (23), 4450-4453.

[27] Kim, H.; Jin, K. Y.; Ha, T. H.; Yu, C.-M. A Convenient Method for the Synthesis of Allenoates from 4-Hydroxyalk-2-ynoates with $\mathrm{PPh}_{3}$. Bull. Korean Chem. Soc. 2013, 34(3), 719-720.

[28] Fox, D. J.; Medlock, J. A.; Vosser, R.; Warren, S. Allene Synthesis by an Asymmetric Baylis-Hillman Style Reaction on Vinylphosphine Oxides. J. Chem. Soc., Perkin Trans. 1 2001, 2240-2249.

[29] For representative examples, see: (a) Wadsworth, W. S.; Emmons, W. D. The Utility of Phosphonate Carbanions in Olefin Synthesis. J. Am. Chem. Soc. 1961, 83 (7), 1733-1738. (b) Bestmann, H. J.; Hartung, H. Neue Synthese von Allencarbonsäureestern. Angew. Chem. 1963, 75 (6), 297-297. (c) Liu, W.-B.; He, H.; Dai, L.-X.; You, S.-L. A One-Pot Palladium-Catalyzed Allylic Alkylation and Wittig Reaction of Phosphorus Ylides. Chem. Eur. J. 2010, 16 (25), 7376-7379. (d) Zhang, K.; Lu, L.-Q.; Yao, S.; Chen, J.-R.; Shi, D.-Q.; Xiao, W.-J. Enantioconvergent Copper Catalysis: In Situ Generation of the Chiral Phosphorus Ylide and Its Wittig Reactions. J. Am. Chem. Soc. 2017, 139 (36), 12847-12854. (e) Pierrot, D.; Presset, M.; Rodriguez, J.; Bonne, D.; Coquerel, Y. Normal, Abnormal, and Cascade Wittig Olefinations of $\alpha$-Oxoketenes. Chem. Eur. J. 2018, 24 (43), 1111011118.

[30] Sano, S.; Matsumoto, T.; Yano, T.; Toguchi, M.; Nakao, M. Synthesis of Allenyl Esters by Horner-Wadsworth-Emmons Reactions of Ketenes Mediated by Isopropylmagnesium Bromide. Synlett 2015, 26 (15), 2135-2138.

[31] Cardoso, A. L.; Henriques, M. S. C.; Paixão, J. A.; Pinho e Melo, T. M. V. D. (1H-Tetrazol-5-yl)-Allenes: Building Blocks for Tetrazolyl Heterocycles. J. Org. Chem. 2016, 81 (19), 9028-9036.

[32] (a) Tömösközi, I.; Bestmann, H. J. Partielle Asymetrische Synthese Und Absolute Konfiguration von Allencarbonsauren. Tetrahedron Lett. 1964, 5 (20), 1293-1295. (b) Jürgen, H.; Bestmann; Tömösközi, I. Reaktionen Mit Alkylidenephosphoranen-XVIII: Kinetische Racematspaltungen durch Umsetzung von Alkylidenphosphoranen mit Optisch Aktiven Säurechloriden. Tetrahedron 1968, 24 (8), 32993319.

[33] (a) Musierowicz, S.; Wróblewski, A. E. Asymmetric Synthesis of 4,4Disubstituted Alka-2,3-Dienoates. Tetrahedron 1980, 36 (10), 13751380. (b) Musierowicz, S.; Wróblewski, A.; Krawczyk, H. Stereochemistry of P-Chiral Phosphinylacetic Acid Esters I Asymmetric Synthesis of Substituted Alkadiene-1,2-Carboxylic-1 and $\delta$-Chiral $\alpha, \beta$-Unsaturated Carboxylic Acid Esters. Tetrahedron Lett. 1975, 16 (7), 437-440.

[34] Tanaka, K.; Otsubo, K.; Fuji, K. Enantioselective Preparation of Allenecarboxylates by Asymmetric Horner-Wadsworth-Emmons Reaction. Tetrahedron Lett. 1996, 37 (21), 3735-3738.

[35] Yamazaki, J.; Watanabe, T.; Tanaka, K. Enantioselective Synthesis of Allenecarboxylates from Phenyl Acetates through $\mathrm{C}-\mathrm{C}$ Bond Forming Reactions. Tetrahedron: Asymmetry. 2001, 12 (4), 669-675.

[36] (a) Pinho e Melo, T. M. V. D.; Cardoso, A. L.; Rocha Gonsalves, A. M. d’A.; Storr, R. C.; Pessoa, J. C.; Paixão, J. A.; Beja, A. M.; Silva, M. R. Contribution to the Synthesis of Chiral Allenic Esters. Tetrahedron Lett. 2003, 44 (34), 6409-6412. (b) Pinho e Melo, T. M. V. D.; Cardoso, A. L.; Gonsalves, A. M. d’A R.; Pessoa, J. C.; Paixão, J. A.; Beja, A. M. Novel Asymmetric Wittig Reaction: Synthesis of Chiral Allenic Esters. Eur. J. Org. Chem. 2004, 2004 (23), 4830-4839.

[37] (a) Li, C.-Y.; Sun, X.-L.; Jing, Q.; Tang, Y. Enantioselective Synthesis of Allenic Esters via an Ylide Route. Chem. Commun. 2006, 2980 2982. (b) Li, C.-Y.; Zhu, B.-H.; Ye, L.-W.; Jing, Q.; Sun, X.-L.; Tang, Y.; Shen, Q. Olefination of Ketenes for the Enantioselective Synthesis of Allenes via an Ylide Route. Tetrahedron 2007, 63 (33), 8046-8053. 
[38] Li, C.-Y.; Wang, X.-B.; Sun, X.-L.; Tang, Y.; Zheng, J.-C.; Xu, Z.-H.; Zhou, Y.-G.; Dai, L.-X. Iron Porphyrin-Catalyzed Olefination of Ketenes with Diazoacetate for the Enantioselective Synthesis of Allenes. J. Am. Chem. Soc. 2007, 129 (6), 1494-1495.

[39] Tsubouchi, A.; Kira, T.; Takeda, T. Peterson Allenation Using (Z)-(1Lithio-1-Alkenyl)Trimethylsilanes. Synlett 2006 (16), 2577-2580.

[40] Lee, D.; Danishefsky, S. J. Cascade Resulting in the Reductive Ethynylation of Aldehydes: Dissection of Its Components. J. Am. Chem. Soc. 2010, 132 (12), 4427-4430.

[41] (a) Chan, T. H.; Mychajlowskij, W. The Synthesis of Alkenes from Carbonyl Compounds and Carbanions Alpha to Silicon, II: 1,2Alkadienes. Tetrahedron Lett. 1974, 15 (2), 171-174. (b) Chan, T. H.; Mychajlowskij, W.; Ong, B. S.; Harpp, D. N. Synthesis of Alkenes from Carbonyl Compounds and Carbanions Alpha. to Silicon 6. Synthesis of Terminal Allenes and Allyl Chlorides. J. Org. Chem. 1978, 43 (8), 1526-1532.

[42] Tius, M. A.; Pal, S. K. Allenes from Ynals. Tetrahedron Lett. 2001, 42 (14), 2605-2608.

[43] Torres, E.; Larson, G. L.; McGarvey, G. J. An Asymmetric Hydrogen Equivalent: Use of the 1-Naphthylphenylmethylsilyl Group in the Preparation of Optically Active Allyl Alcohols and (S)-1-Phenyl-1,2Butadiene. Tetrahedron Lett. 1988, 29 (12), 1355-1358.

[44] For a similar approach, see: Bratovanov, S.; Bienz, S. Synthesis of Chiral Allenes by Peterson-Type Olefinations. Main Group Met. Chem. 2011, 19 (12), 769-784

[45] Suginome, M.; Matsumoto, A.; Ito, Y. Palladium-Catalyzed Intramolecular Bis-Silylation of Propargylic Alcohols: A New Stereospecific Access to Chiral Allenylsilanes. J. Org. Chem. 1996, 61 (15), 4884-4885.

[46] Barber, J. S.; Yamano, M. M.; Ramirez, M.; Darzi, E. R.; Knapp, R. R.; Liu, F.; Houk, K. N.; Garg, N. K. Diels-Alder Cycloadditions of Strained Azacyclic Allenes. Nature Chem. 2018, 10 (9), 953.

[47] For selected examples, see: (a) Schreck, M.; Christl, M. Generation and Interception of 1-Oxa-3,4-Cyclohexadiene. Angew. Chem. Int. Ed. 1987, 26 (7), 690-692. (b) Quintana, I.; Peña, D.; Pérez, D.; Guitián, E. Generation and Reactivity of 1,2-Cyclohexadiene under Mild Reaction Conditions. Eur. J. Org. Chem. 2009, 32, 5519-5524. (c) Barber, J. S.; Styduhar, E. D.; Pham, H. V.; McMahon, T. C.; Houk, K. N.; Garg, N. K. Nitrone Cycloadditions of 1,2-Cyclohexadiene. J. Am. Chem. Soc. 2016, 138 (8), 2512-2515.

[48] Konoike, T.; Araki, Y. Concise Allene Synthesis from Propargylic Alcohols by Hydrostannation and Deoxystannylation: A New Route to Chiral Allenes. Tetrahedron Lett. 1992, 33 (35), 5093-5096.

[49] (a) Fletcher, M. T.; McGrath, M. J.; König, W. A.; Moore, C. J.; Cribb, B. W.; Allsopp, P. G.; Kitching, W. A Novel Group of Allenic Hydrocarbons from Five Australian (Melolonthine) Beetles. Chem. Commun. 2001, 885-886. (b) McGrath, M. J.; Fletcher, M. T.; König, W. A.; Moore, C. J.; Cribb, B. W.; Allsopp, P. G.; Kitching, W. A Suite of Novel Allenes from Australian Melolonthine Scarab Beetles. Structure, Synthesis, and Stereochemistry. J. Org. Chem. 2003, 68 (10), 3739-3748.

[50] Rigby, J. H.; Laurent, S. B.; Kamal, Z.; Heeg, M. J. Chromium(0)Promoted $[6 \pi+2 \pi]$ Cycloadditions of Allenes with Cycloheptatriene. Org. Lett. 2008, 10 (24), 5609-5612.

[51] Zhao, Y.; Quayle, P.; Kuo (née Mason), E. A. The Stereoselective Functionalisation of 1,1-Bis-(Tributylstannyl)Ethenes. Tetrahedron Lett. 1994, 35 (22), 3797-3800.

[52] Hailes, H. C.; Isaac, B.; Javaid, M. H. The Synthesis of 2-Alkylated Cyclopentene-1,3-Diones: Novel Compounds with Olfactory Properties. Synth. Commun. 2003, 33 (1), 29-41.

[53] Endo, T.; Sasaki, F.; Hara, H.; Suzuki, J.; Tamura, S.; Nagata, Y.; Iyoshi, T.; Saigusa, A.; Nakano, T. A Highly Efficient Synthesis of (Z)-1-Aryl-2-Silyl-1-Stannylethenes and Their Conversion to $(E)$-2Arylethenyl-, (Z)-2-(2-Pyridyl)Ethenyl- and Allenyl-Silanes. Appl. Organomet. Chem. 2007, 21 (3), 183-197.

[54] Nativi, C.; Ricci, A.; Taddei, M. A Simple Synthesis of 1Trimethylsilyl-2,3-Dienes. Tetrahedron Lett. 1987, 28 (24), 27512752.

[55] Pelter, A.; Smith, K.; Jones, K. D. Allene Synthesis via BoronStabilised Alkenyl Carbanions. J. Chem. Soc., Perkin Trans. 1 1992, 747-748.

[56] Kim, B.-S.; Hussain, M. M.; Hussain, N.; Walsh, P. J. PalladiumCatalyzed Chemoselective Allylic Substitution, Suzuki-Miyaura Cross-Coupling, and Allene Formation of Bifunctional 2-B(Pin)Substituted Allylic Acetate Derivatives. Chem. Eur. J. 2014, 20 (37), $11726-11739$.
[57] Wesquet, A. O.; Kazmaier, U. Distannylations and Silastannylations of In Situ Generated Allenes. Angew. Chem. Int. Ed. 2008, 47 (16), 30503053.

[58] Armstrong, R. J.; Nandakumar, M.; Dias, R. M. P.; Noble, A.; Myers, E. L.; Aggarwal, V. K. Enantiodivergent Synthesis of Allenes by Point-to-Axial Chirality Transfer. Angew. Chem. Int. Ed. 2018, 57 (27), 8203-8208.

[59] Armstrong, R. J.; García-Ruiz, C.; Myers, E. L.; Aggarwal, V. K. Stereodivergent Olefination of Enantioenriched Boronic Esters. Angew. Chem. Int. Ed. 2017, 56 (3), 786-790.

[60] Shono, T.; Ito, K.; Tsubouchi, A.; Takeda, T. Titanocene(II)-Promoted Carbonyl Allenation Utilizing 1,1-Dichloroalk-1-Enes. Org. Biomol. Chem. 2005, 3 (16), 2914-2916.

[61] Buchwald, S. L.; Grubbs, R. H. A Titanium Vinylidene Route to Substituted Allenes. J. Am. Chem. Soc. 1983, 105 (16), 5490-5491.

[62] Yoshida, T.; Negishi, E. 1,1-Dimetalloalkenes Containing Aluminum as Well as Titanium or Zirconium. Their Structures and Use as Novel Alkenylidene and Alkenyl Transfer Agents. J. Am. Chem. Soc. 1981, 103 (5), 1276-1277.

[63] Petasis, N. A.; Hu, Y.-H. Allenation of Carbonyl Compounds with Alkenyltitanocene Derivatives. J. Org. Chem. 1997, 62 (4), 782-783.

[64] Ogata, A.; Nemoto, M.; Kobayashi, K.; Tsubouchi, A.; Takeda, T. Titanocene(II)-Promoted Multicomponent Reactions Utilizing Alkynyl Sulfones, Alkenyl Sulfones, and Carbonyl Compounds: A Novel Method for the Synthesis of Vinylallenes. Chem. Eur. J. 2007, 13 (4), $1320-1325$.

[65] Tucker, C. E.; Greve, B.; Klein, W.; Knochel, P. Preparation of Polyfunctional Olefins and Allenes Using 1,1-Bimetallics of Zinc and Zirconium. Organometallics 1994, 13 (1), 94-101.

[66] Zhou, H.; Liu, G.; Zeng, C. Bismetalated Carbon for Tandem WittigType Reaction via Allylgallation of Magnesium Acetylides: A Convenient and Efficient Method to Allyl Allenes. J. Organomet. Chem. 2008, 693 (4), 787-791.

[67] Pu, X.; Ready, J. M. Direct and Stereospecific Synthesis of Allenes via Reduction of Propargylic Alcohols with $\mathrm{Cp}_{2} \mathrm{Zr}(\mathrm{H}) \mathrm{Cl}$. J. Am. Chem. Soc. 2008, 130 (33), 10874-10875.

[68] Satoh, T.; Sakamoto, T.; Watanabe, M. A Novel Synthesis of Allenes by Alkenylation of Magnesium Alkylidene Carbenoids with Lithium $\alpha$-Sulfonyl Carbanions. Tetrahedron Lett. 2002, 43 (11), 2043-2046.

[69] Satoh, T.; Kaneta, H.; Matsushima, A.; Yajima, M. A New Synthesis of $\beta, \gamma$-Unsaturated Esters and Allenic Esters with Construction of a Carbon-carbon Bond between $\alpha$ - and $\beta$-Positions by the Reaction of Magnesium Alkylidene Carbenoids with Lithium Ester Enolates. Tetrahedron Lett. 2009, 50 (46), 6280-6285.

[70] Mori, N.; Obuchi, K.; Katae, T.; Sakurada, J.; Satoh, T. Alkenylation of Thiophenes and Furans at the 2-Position and a Synthesis of Allenes Conjugated with $\alpha, \beta$-Unsaturated Ester with Magnesium Alkylidene Carbenoids. Tetrahedron 2009, 65 (17), 3509-3517.

[71] Kimura, T.; Kobayashi, G.; Ishigaki, M.; Inumaru, M.; Sakurada, J.; Satoh, T. Coupling Reaction of Magnesium Alkylidene Carbenoids with $\alpha$-Sulfonylallyllithiums: An Efficient Route to Multi-Substituted Vinylallenes. Synthesis 2012, 44 (23), 3623-3632.

[72] Zhu, M.; Liu, L.; Yu, H.-T.; Zhang, W.-X.; Xi, Z. Alkenyl Magnesium Compounds: Generation and Synthetic Application. Chem. Eur. J. 2018, 24 (72), 19122-19135.

[73] (a) Satoh, T.; Kuramochi, Y.; Inoue, Y. A New Method for Synthesis of Allenes, Including an Optically Active Form, from Aldehydes and Alkenyl Aryl Sulfoxides with Carbon-carbon Bond-Formation. Tetrahedron Lett. 1999, 40 (50), 8815-8818. (b) Satoh, T.; Hanaki, N.; Kuramochi, Y.; Inoue, Y.; Hosoya, K.; Sakai, K. A New Method for Synthesis of Allenes, Including an Optically Active Form, from Aldehydes and Alkenyl Aryl Sulfoxides by Sulfoxide-metal Exchange as the Key Reaction and an Application to a Total Synthesis of Male Bean Weevil Sex Attractant. Tetrahedron 2002, 58 (13), 2533-2549.

[74] Zhang, Y.; Wu, Y. An Elimination Approach to the Synthesis of (+)Scorodonin. Chin. J. Chem. 2010, 28 (9), 1635-1639.

[75] Zhang, Y.; Hao, H.-D.; Wu, Y. An 1,2-Elimination Approach to the Enantioselective Synthesis of 1,3-Disubstituted Linear Allenes. Synlett 2010 (6), 905-908.

[76] Zhang, Y.; Wu, Y. An Enantioselective Total Synthesis of Natura Antibiotic Marasin. Org. Biomol. Chem. 2010, 8 (20), 4744-4752.

[77] For reporesentative examples, see: (a) Hässig, R.; Seebach, D.; Siegel, $\mathrm{H}$. Herstellung von Allenen aus geminalen Dibromolefinen und Aldehyden. Chem. Ber. 1984, 117 (5), 1877-1884. (b) Gabbutt, C. D. Hepworth, J. D.; Heron, B. M.; Rahman, M. M. Allenes from 3- 
Bromo-2H-1-Benzopyrans. J. Chem. Soc., Perkin Trans. 1 1994, 13, $1733-1737$.

[78] Barluenga, J.; Fernández, J. R.; Yus, M. Alka-2,3-Dienes from Crotonaldehyde. J. Chem. Soc., Chem. Commun. 1985, 4, 203-204.

[79] Yokota, M.; Fuchibe, K.; Ueda, M.; Mayumi, Y.; Ichikawa, J. Facile Synthesis of 1,1-Difluoroallenes via the Difluorovinylidenation of Aldehydes and Ketones. Org. Lett. 2009, 11 (17), 3994-3997.

[80] (a) Oh, K.; Fuchibe, K.; Ichikawa, J. A Facile Synthesis of 1,1Difluoroallenes from Commercially Available 1,1,1-Trifluoro-2Iodoethane. Synthesis 2011, 6, 881-886. (b) Oh, K.; Fuchibe, K.; Ichikawa, J. A Facile Synthesis of 1,1-Difluoroallenes from Commercially Available 1,1,1-Trifluoro-2-Iodoethane. Synthesis 2011, 6, 881-886.

[81] Fuchibe, K.; Mayumi, Y.; Zhao, N.; Watanabe, S.; Yokota, M.; Ichikawa, J. Domino Synthesis of Fluorine-Substituted Polycyclic Aromatic Hydrocarbons: 1,1-Difluoroallenes as Synthetic Platforms. Angew. Chem. Int. Ed. 2013, 52 (30), 7825-7828.

[82] Yamazaki, T.; Yamamoto, T.; Ichihara, R. Preparation of $\mathrm{CF}_{3^{-}}$ Containing 1,3-Di- and 1,1,3-Trisubstituted Allenes. J. Org. Chem. 2006, 71 (16), 6251-6253.

[83] For a related process involving $\mathrm{SmI}_{2}$ mediated reduction, see: Yoshimatsu, M.; Hibino, M. First Synthesis of a $\alpha$-Trifluoromethyl Allenol Ether via the Julia-Lythgoe Process. Chem. Pharm. Bull. 2000, 48 (9), 1395-1398.

[84] Sam, B.; Montgomery, T. P.; Krische, M. J. Ruthenium Catalyzed Reductive Coupling of Paraformaldehyde to Trifluoromethyl Allenes: $\mathrm{CF}_{3}$-Bearing All-Carbon Quaternary Centers. Org. Lett. 2013, 15 (14), 3790-3793.

[85] Lin, M.-H.; Tsai, W.-S.; Lin, L.-Z.; Hung, S.-F.; Chuang, T.-H.; Su, Y.-J. Methods for the Preparation of Allenes Employing Indium- and Zinc-Mediated Dehalogenation Reactions in Aqueous Solutions. $J$. Org. Chem. 2011, 76 (20), 8518-8523.

[86] (a) Varghese, J. P.; Knochel, P.; Marek, I. New Allene Synthesis via Carbocupration-Zinc Carbenoid Homologation and $\beta$-Elimination Sequence. Org. Lett. 2000, 2 (18), 2849-2852. (b) Varghese, J. P.; Zouev, I.; Aufauvre, L.; Knochel, P.; Marek, I. Carbocupration/Zinc Carbenoid Homologation and $\beta$-Elimination Reactions for a New Synthesis of Allenes - Application to the Enantioselective Synthesis of Chiral Allenes by Deracemization of $\mathrm{Sp}^{3}$-Organometallic Derivatives. Eur. J. Org. Chem. 2002, 24, 4151-4158.

[87] Ohno, H.; Toda, A.; Oishi, S.; Tanaka, T.; Takemoto, Y.; Fujii, N.; Ibuka, T. Novel Synthesis of Chiral Terminal Allenes via Palladium(0)-Catalyzed Reduction of Mesylates of 2-Bromoalk-2-En1-Ols Bearing a Protected Amino Group, Using Diethylzinc. Tetrahedron Lett. 2000, 41 (26), 5131-5134.

[88] Ohno, H.; Miyamura, K.; Tanaka, T.; Oishi, S.; Toda, A.; Takemoto, Y.; Fujii, N.; Ibuka, T. Synthesis of Allenes from Allylic Alcohol Derivatives Bearing a Bromine Atom Using a Palladium(0)/Diethylzinc System. J. Org. Chem. 2002, 67 (4), 13591367.

[89] Semmelhack, M. F.; Brickner, S. J. Nickel-Promoted Cyclization/Carbonylation in the Preparation of Alpha-MethyleneGamma Lactones. Stereospecific Synthesis of (+-)-Frullanolide. J. Am. Chem. Soc. 1981, 103 (13), 3945-3947.

[90] de la Pradilla, R. F.; Rubio, M. B.; Marino, J. P.; Viso, A. Evidence for "Stable" Organocopper Intermediates in the Reaction between $\mathrm{Me}_{2} \mathrm{CuLi} \cdot \mathrm{LiI}$ and Allylic Sulfinyl Mesylates. Tetrahedron Lett. 1992, 33 (34), 4985-4988.

[91] Lukas, J.; Visser, J. P.; Kouwenhoven, A. P. The Formation of Allenes via $\mathrm{Pd}^{\mathrm{II}}$ and $\mathrm{Pt}^{\mathrm{II}}$ Complexes. J. Organomet. Chem. 1973, 50 (1), 349351.

[92] Danheiser, R. L.; Choi, Y. M.; Menichincheri, M.; Stoner, E. J. Synthesis of Allenes via Thermal Cycloreversion of Alpha-AlkylideneBeta-Lactones. J. Org. Chem. 1993, 58 (2), 322-327.

[93] Aronica, L. A.; Mazzoni, C.; Caporusso, A. M. Synthesis of Functionalised $\beta$-Lactones via Silylcarbocyclisation/Desilylation Reactions of Propargyl Alcohols. Tetrahedron 2010, 66 (1), 265-273.

[94] Martínez, I.; Andrews, A. E.; Emch, J. D.; Ndakala, A. J.; Wang, J.; Howell, A. R. Unusual, Strained Heterocycles: 3-Alkylidene-2Methyleneoxetanes from Morita-Baylis-Hillman-Type Adducts. Org. Lett. 2003, 5 (4), 399-402.

[95] (a) Kolakowski, R. V.; Manpadi, M.; Zhang, Y.; Emge, T. J.; Williams, L. J. Allene Synthesis via $\mathrm{C}-\mathrm{C}$ Fragmentation: Method and
Mechanistic Insight. J. Am. Chem. Soc. 2009, 131 (36), 12910-12911. (b) Xu, D.; Drahl, M. A.; Williams, L. J. Toward an Integrated Route to the Vernonia Allenes and Related Sesquiterpenoids. Beilstein J. Org. Chem. 2011, 7 (1), 937-943.

[96] Saget, T.; Cramer, N. Heteroatom-Nucleophile-Induced C-C Fragmentations: Synthesis of Allenes and Entry to Domino Reactions. Angew. Chem. Int. Ed. 2010, 49 (47), 8962-8965.

[97] (a) Delouvrié, B.; Lacôte, E.; Fensterbank, L.; Malacria, M. A New Radical Synthesis of Allenes. Tetrahedron Lett. 1999, 40 (18), 35653568. (b) Mouriès, V.; Delouvrié, B.; Lacôte, E.; Fensterbank, L.; Malacria, M. Radical $\beta$-Elimination of a Sulfinyl Group to Afford Allenes. Eur. J. Org. Chem. 2002, 11, 1776-1787.

[98] Han, H. Y.; Kim, M. S.; Son, J. B.; Jeong, I. H. Novel Synthesis of 1Aryl-1-Trifluoromethylallenes. Tetrahedron Lett. 2006, 47 (2), 209212. 